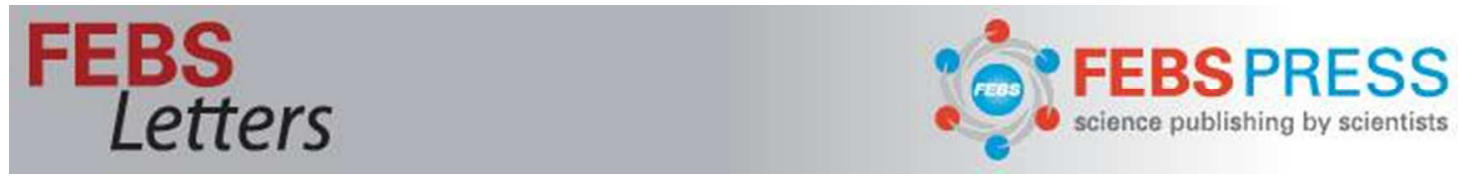

\title{
Pneumococcal lipoproteins involved in bacterial fitness, virulence and immune evasion
}

\begin{tabular}{|c|c|}
\hline Journal: & FEBS Letters \\
\hline Manuscript ID & FEBSL-16-0760.R1 \\
\hline Wiley - Manuscript type: & Review \\
\hline Date Submitted by the Author: & $n / a$ \\
\hline Complete List of Authors: & $\begin{array}{l}\text { Kohler, Sylvia; Ernst-Moritz-Arndt Universitat Greifswald, Department } \\
\text { Genetics of Microorganisms, Interfaculty Institute for Genetics and } \\
\text { Functional Genomics } \\
\text { Voss, Franziska; Ernst-Moritz-Arndt Universitat Greifswald, Department } \\
\text { Genetics of Microorganisms, Interfaculty Institute for Genetics and } \\
\text { Functional Genomics } \\
\text { Gómez, Alejandro; Ernst-Moritz-Arndt Universitat Greifswald, Department } \\
\text { Genetics of Microorganisms, Interfaculty Institute for Genetics and } \\
\text { Functional Genomics } \\
\text { Brown, Jeremy; University College London Medical School, Centre for } \\
\text { Inflammation and Tissue Repair } \\
\text { Hammerschmidt, Sven; Ernst-Moritz-Arndt Universitat Greifswald, } \\
\text { Department Genetics of Microorganisms, Interfaculty Institute for Genetics } \\
\text { and Functional Genomics }\end{array}$ \\
\hline \multicolumn{2}{|l|}{ Keywords: } \\
\hline Abstract: & $\begin{array}{l}\text { Streptococcus pneumoniae (pneumococcus) has evolved sophisticated } \\
\text { strategies to survive in several niches within the human body either as a } \\
\text { harmless commensal or as a serious pathogen causing a variety of } \\
\text { diseases. The dynamic interaction between pneumococci and resident host } \\
\text { cells during colonization of the upper respiratory tract and at the site of } \\
\text { infection is critical for bacterial survival and the development of disease. } \\
\text { Pneumococcal lipoproteins are peripherally anchored membrane proteins } \\
\text { and have pivotal roles in bacterial fitness including envelope stability, cell } \\
\text { division, nutrient acquisition, signal transduction, transport (as substrate- } \\
\text { binding proteins of ABC transporter systems), resistance to oxidative stress } \\
\text { and antibiotics, and protein folding. In addition, lipoproteins are directly } \\
\text { involved in }\end{array}$ \\
\hline
\end{tabular}




\section{Pneumococcal lipoproteins involved in bacterial fitness, virulence and immune evasion}

Sylvia Kohler ${ }^{1}$, Franziska Voß ${ }^{1}$, Alejandro Gómez Mejia ${ }^{1}$, Jeremy S. Brown ${ }^{2}$, and Sven Hammerschmidt $^{1 *}$

${ }^{1}$ Department Genetics of Microorganisms, Interfaculty Institute for Genetics and Functional Genomics, University of Greifswald, Greifswald, Germany

${ }^{2}$ Centre for Inflammation and Tissue Repair, Department of Medicine, University College Medical School, London, United Kingdom

*For correspondence: Prof. Dr. Sven Hammerschmidt, Department Genetics of Microorganisms, Interfaculty Institute for Genetics and Functional Genomics, University of Greifswald, Friedrich-Ludwig-Jahn-Strasse 15a, 17487 Greifswald, Germany, phone: +49 3834 864161, Fax: +49 3834 864172, E-mail: sven.hammerschmidt@uni-greifswald.de.

Funding: This work was supported by Grants from the Deutsche Forschungsgemeinschaft DFG-GRK1870 (to SH), Meningitis Now and the Department of Health's NIHR Biomedical Research Centre's funding scheme (to JSB). 


\section{Summary}

Streptococcus pneumoniae (pneumococcus) has evolved sophisticated strategies to survive in several niches within the human body either as a harmless commensal or as a serious pathogen causing a variety of diseases. The dynamic interaction between pneumococci and resident host cells during colonization of the upper respiratory tract and the site of infection is critical for bacterial survival and the development of disease. Pneumococcal lipoproteins are peripherally anchored membrane proteins and have pivotal roles in bacterial fitness including envelope stability, cell division, nutrient acquisition, signal transduction, transport (as substrate-binding proteins of $A B C$ transporter systems), resistance to oxidative stress and antibiotics, and protein folding. In addition, lipoproteins are directly involved in virulenceassociated processes such as adhesion, colonization, and persistence through immune evasion. Conversely, lipoproteins are also targets for the host response both as ligands for toll like receptors and as targets for acquired antibody. This review summarizes the multifaceted roles of selected pneumococcal lipoproteins and how this knowledge can be exploited to combat pneumococcal infections.

\section{Keywords}

Streptococcus pneumoniae, lipoprotein, virulence, immune response, antibacterial therapy

\section{Introduction}

Streptococcus pneumoniae (pneumococcus) is a Gram-positive human-specific commensal of the upper and lower respiratory tract. Under certain circumstances, particularly in immunedeficient individuals, young children, and elderly persons, pneumococci can also cause noninvasive infections such as otitis media and sinusitis, and life-threatening diseases such as meningitis, septicaemia, and pneumonia [1, 2]. Pneumococcal colonization of the nasopharyngeal epithelium and subsequent dissemination of pneumococci into other parts of the human body to cause disease are highly dynamic processes [3]. Multiple bacterial surface-displayed or released molecules contribute to direct and indirect interactions with the host such as adhesion and invasion. In addition, they help to maintain bacterial survival within the host by physiological adaptation and immune evasion [4-6]. The polysaccharide capsule (CPS) is the sine qua non virulence determinant of $S$. pneumoniae as it protects against mucus-mediated clearance, uptake by professional phagocytes and facilitates pneumococcal escape from neutrophil extracellular traps. The CPS has a variable structure between pneumococcal strains and is divided into more than 90 serotypes differing in their efficacy for promoting immune evasion [7-10]. The pneumococcal capsule masks other bacterial surface components such as the cell wall coated with phosphorylcholine (PCho)containing teichoic acids (TAs) and proteins, thus preventing an intimate contact of 
pneumococci with host cells or tissues. However, upon phase variation from an opaque to a transparent phenotype, less CPS is produced and higher amounts of TAs and PCho are detectable in the pneumococcal cell wall [11-13]. The increased accessibility of surfaceexposed components may allow $S$. pneumoniae to survive, multiply and spread into new niches of the human host. For instance, pneumococcal surface proteins play critical roles in virulence as they maintain bacterial viability and participate in different stages of infection, including adhesion, colonization, invasion, immune evasion and dissemination into various host tissues and organs [4-6]. Four classes of proteins have been distinguished according to their anchoring mechanism: i) choline-binding proteins that are non-covalently attached to cell wall PCho, ii) proteins carrying an LPxTG motif can be covalently incorporated into the peptidoglycan polymer in a sortase-dependent manner, iii) non-classical surface proteins (NCSP), also referred to as moonlighting proteins, that are surface-associated but do not possess classical secretory and anchoring motifs, and iv) lipoproteins that are covalently bound to the cytoplasmic membrane by the action of lipoprotein diacylglyceryl transferase (Lgt) and lipoprotein signal peptidase II (Lsp). Lipoproteins are the subject of this review.

Genes encoding for putative lipoproteins are distributed throughout the pneumococcal genome and yet almost equally located on the positive or negative strand (Figure 1). It has been estimated that lipoproteins account for approximately $2-3 \%$ of the pneumococcal proteome and about $40 \%$ of the indicated and predicted pneumococcal surface proteins [14, 15]. A large proportion of pneumococcal lipoproteins are substrate-binding proteins (SBPs) of $A B C$ transporter systems responsible for the acquisition of multiple nutrients including amino acids and short peptides, sugars, polyamines, and various metal ions. Other functions of lipoproteins in S. pneumoniae include folding of excreted proteins, antibiotic and oxidative stress resistance, cell shape maintenance and enzymatic activity $[6,16]$. The contribution of lipoproteins to the virulence of $S$. pneumoniae has been studied extensively and they have been linked to crucial processes in the pathogenesis of pneumococcal infectious diseases such as adhesion, invasion, and immune evasion [17-21]. Moreover, lipoproteins trigger the activation of host innate immune responses via Toll-like receptor 2 (TLR2), which contributes to the establishment of cellular and humoral adaptive immune responses [22, 23]. Therefore, lipoproteins have emerged as promising candidates for the development of novel vaccines and therapeutics against severe pneumococcal infections [24, 25]. Moreover, due to their uniqueness in prokaryotes and their importance for anchoring and further processing of secreted lipoproteins, lipoprotein maturation enzymes are also potential candidates for the development of novel antimicrobials, thus providing another valuable therapeutic aspect for the treatment of pneumococcal disease. 


\section{Pneumococcal Lipoproteins}

\subsection{Lipoprotein Biosynthesis, Maturation, and Localization}

Like in other bacteria, pneumococcal lipoproteins are initially translated in the cytoplasm as preprolipoproteins containing a classical N-terminal signal peptide followed by a Lipobox motif (LVI)(ASTVI)(GAS)C. After export via the sec or tat secretion machineries, lipoprotein diacylglyceryl transferase (Lgt) catalyzes the covalent attachment of the lipoprotein precursor at its indispensable cysteine residue within the Lipobox to phosphatidylglycerol of the cytoplasmic membrane. Afterwards, lipoprotein signal peptidase II (Lsp) cleaves the signal peptide of the prolipoprotein leaving the lipidated cysteine as new amino-terminal residue (Figure 2) [26]. Lgt and Lsp are conserved in all bacteria, whereas lipoprotein $\mathrm{N}$ acyltransferase (Lnt), a third lipoprotein-modifying enzyme downstream of Lgt and Lsp, was thought to be present only in Gram-negative bacteria [27]. However, Lnt homologues have been identified in several high-GC bacteria and a lipoprotein of Staphylococcus aureus was found to be $\mathrm{N}$-acylated by a so far unidentified enzyme [28].

Bacterial lipoproteins have formerly been classified into nine clusters, according to their sequence similarities [29, 30]. However, due to increasingly available structural data, a new classification based on structural similarity has been introduced, now numbering cluster A to $F$ [31]. The in silico analysis predicted up to 37 lipoproteins in S. pneumoniae serotype 2 and 4 according to their Lipobox motif $[15,32]$. Recently, a comprehensive proteomic analysis has been performed to elucidate the global surface and exoproteome of $S$. pneumoniae, including the role of lipoprotein maturation on the protein composition of the bacterial cell envelope and extracellular milieu. Optimization of a biotinylation approach allowed the identification of $95 \%$ of the 35 predicted surface-exposed lipoproteins of a nonencapsulated D39 strain, among them, two out of four hypothetical lipoproteins with unknown functions [15]. As expected, the majority of lipoproteins accumulated in the culture supernatant after deletion of $\Delta / g t$, indicating improper anchoring in the cytoplasmic membrane. Deletion of $\Delta / s p$ resulted in higher molecular weight protein bands in immunoblots compatible to retention of $\mathrm{N}$-terminal signal peptide-containing lipoproteins (Figure 3) [15, 33]. Nevertheless, the protein amount detectable on the surface and in the exoproteome of the $\Delta / g t$ and $\Delta / s p$ mutants varied substantially between the different lipoproteins due to either rapid degradation or higher expression, respectively [15]. It has yet to be determined whether unprocessed lipoproteins are still at least partially functional when retained on the pneumococcal surface. Some of the phenotypes of the $S$. pneumoniae $\Delta / g t$ mutant are weaker than deletion of the relevant lipoprotein suggesting some residual lipoprotein functionality even when the processing has been disrupted as recently described for the DacB lipoprotein [15, 17, 33]. Similar to previous studies, additional lower molecular 
weight signals for the streptococcal lipoprotein rotamase A (SIrA) lipoprotein were detectable in the $\Delta / s p$ mutant suggesting another signal peptidase or membrane protease can substitute for loss of the primary signal peptidase Lsp (Figure 2) [15, 34]. Therefore, a model for maturation of lipoproteins has been proposed accounting for alternative processing in the absence of Lsp [15, 34].

\section{A General view on the Role of Pneumococcal Lipoproteins for Bacterial Fitness and Virulence}

Lipoproteins are involved in many important cellular processes and generally classified into different functional groups, e.g. substrate-binding for $A B C$ transporter systems, resistance to antibiotics, cell envelope stability, and protein folding. However, several lipoproteins are multifunctional and their roles overlap these categories. In some cases redundant functions of several lipoproteins can be explained by a conserved overall three-dimensional structure, despite their variation in size and low sequence similarity [21, 30, 31]. In contrast, incomplete maturation of lipoproteins due to functional deficiency of Lgt, Lsp or both enzymes has significant but pleiotropic effects on metabolic and virulence functions modulating bacterial survival and pathogenesis in the human host [15, 33-35]. However, the impact of $\Delta / g t$ or $\Delta / s p$ mutations on growth and virulence strongly depends on the bacterial species and strain as well as on the animal infection model employed in the respective study. For example, a $\Delta / g t$ mutant of Streptococcus equi was attenuated in a mouse model of infection but not in the horse serving as natural host [36]. Likewise, deficiency of Lsp caused an impaired intracellular growth and moderate attenuation in virulence of Listeria monocytogenes while no effect on virulence was detectable for $S$. suis $[37,38]$. In $S$. pneumoniae, functional deficiency of Lgt had no effect on bacterial growth in artificial media but resulted in a significant growth defect in blood and bronchoalveolar lavage fluids representing physiologically relevant infection conditions [15, 33]. The identified phenotypes of $\Delta / g t$ and $\Delta / s p$ mutants strongly associated with defective functions of several $A B C$ transporters. For instance, a higher susceptibility of these mutants to oxidative stress can be attributed to impaired uptake of divalent cations and, consequently, to low intracellular concentrations of manganese ions usually imported by the lipoprotein pneumococcal surface adhesion $A$ (PsaA) (Section 2.2.1.) [33]. Importantly, $\Delta / g t$ mutants of $S$. pneumoniae are avirulent in mouse models of pneumonia and septicaemia and show a decreased capacity to colonize the nasopharynx $[33,35]$. Pneumococcal mutants deficient in the signal peptidase Lsp displayed only moderate defects in growth in complex media but had impaired growth in blood, which is compatible with a significantly reduced virulence in mouse infection models of pneumonia and septicaemia [15, 34]. 


\subsection{Functions of Pneumococcal classical Non-ABC Transporter Lipoproteins}

The majority of lipoproteins in $S$. pneumoniae are predicted to be part of $A B C$ importer systems. However, the pneumococcal genome also encodes for several lipoproteins not associated with $A B C$ transporters crucial for bacterial fitness and full virulence (Table 1) [32, 39]. For instance, six lipoproteins have been implicated in folding or activation of surfaceexposed proteins, such as the peptidyl-prolyl isomerases (PPlases) putative proteinase maturation protein $A(P p m A)$ and SIrA, though PPlase activity was only demonstrated for SIrA [19]. Both PpmA and SIrA have been shown to promote pneumococcal colonization and contribute to virulence in a mouse model of acute pneumonia [18, 19, 39]. In addition, non$A B C$ transporter lipoproteins exert important functions in cell wall biosynthesis and integrity, as demonstrated for the L,D-carboxypeptidase DacB (also known as LdcB), as well as stress responses of $S$. pneumoniae, as recently shown for the extracellular thioredoxin-like lipoproteins Etrx1 and Etrx2 [17, 21, 32, 40].

\subsubsection{Keep the shape: Impact of cell wall hydrolases on pneumococcal pathogenesis}

The cell wall of $S$. pneumoniae is a rigid layer composed of peptide-linked glycan strands (peptidoglycan, PGN) to maintain cell shape and integrity but flexible enough to ensure physiological processes such as cell division, autolysis, DNA uptake, and trafficking of nutrients and ions. In addition, the pneumococcal cell wall contains teichoic acids, either covalently attached to the PGN (wall teichoic acids, WTAs) or anchored to the cytoplasmic membrane (lipoteichoic acids, LTAs). Strikingly, in S. pneumoniae WTAs and LTAs share an identical chemical structure within their repeating units composed of several different sugar residues and contain up to two PCho residues per TA repeat [41]. The first steps of peptidoglycan synthesis occur intracellularly and include i) the addition of five amino acids, known as stem peptide, to UDP-N-acetylmuramic acid (MurNAc), ii) substitution of UMP in the UDP-MurNAc-pentapeptide precursor for undecaprenyl phosphate of the phospholipid bilayer (Lipid I), and iii) transfer of an UDP-N-acetylglucosamine (GICNAc) residue yielding Lipid II [42]. Afterwards, Lipid II is translocated to the extracellular side of the membrane by the flippases FtsW and RodA [42, 43]. In the extracellular face of the cytoplasmic membrane, penicillin-binding proteins (PBPs) catalyse the incorporation of Lipid II into the existing peptidoglycan network in a cell cycle-dependent manner [42]. This also results in release of undecaprenyl pyrophosphate which is flipped back across the membrane, dephosphorylated and can serve again as lipid carrier for new rounds of peptidoglycan synthesis [44]. Within the cell wall, $\mathrm{N}$-acetylamino sugars may be subjected to modification, i.e. acetylation and deacetylation. In addition, pneumococcal stem peptides can be modified by amidation, hydrolysis, and transpeptidation to form direct or dipeptide-containing cross linkages between peptide chains of neighbouring glycan strands [17, 45, 46]. Importantly, formation of 
branched stem peptides and further modification of the peptidoglycan backbone are associated with pneumococcal resistance to antimicrobial agents, thus preventing bacterial cell death and release of immunostimulatory molecules, and consequently increasing the pneumococcal virulence potential [47-50].

Growth and division of $S$. pneumoniae are strictly dependent on the biosynthesis, turnover and remodelling of peptidoglycan, whose complexity is determined by the function of several different enzymes acting either sequentially or in concert [42]. In this regard, PBPs are highly conserved, extracellular membrane-bound enzymes crucial to bacterial growth and division as they catalyse various steps of the PGN biosynthetic pathway [42]. Among them, Penicillin-binding protein 3, also referred to as DacA, exhibits D,D-carboxypeptidase activity cleaving the fifth amino acid residue off the stem peptide to generate tetrapeptides [51]. Subsequently, the L,D-carboxypeptidase DacB (also referred to as LdcB) catalyses the truncation of generated tetrapeptides into tripeptides (Table 1) [52]. Importantly, the presence of tetra- and tripeptide-containing stem peptides enables transpeptidation reactions catalysed by several PBPs to generate direct cross linkages between neighbouring glycan strands [53]. DacB was first described in E. coli and homologues have been identified in Lactococcus lactis and Bacillus species $[40,54,55]$. Barendt et al. first reported a dacB gene in S. pneumoniae likely encoding for an extracellularly anchored 27-kDa protein of 238 amino acids acting downstream of DacA in generating PGN-tripeptides [52]. And very recently, a surface proteome analysis of $S$. pneumoniae D39 confirmed DacB as a lipoprotein processed by the lipoprotein maturation enzymes Lgt and Lsp (Table 1; Figure 3) [15]. The crystal structure of DacB lacking the membrane-anchoring domain (aa 1-55) has been solved independently by Abdullah et al. and Hoyland et al. in 2014. Both structures are almost identical comprising a small $\mathrm{N}$-terminal region formed by a three-stranded, antiparallel $\beta$ sheet and a $V$-shaped catalytic cavity formed by a four-stranded, antiparallel $\beta$-sheet and seven $\alpha$-helices $[17,40]$. However, Abdullah et al. propose two $33_{10}$-helices downstream of $\alpha 3$ and $\alpha 4$, respectively, instead of two extended $\alpha$-helices [17]. Nonetheless, the catalytic site contains a single $\mathrm{Zn}(\mathrm{II})$ ion co-ordinated by a His-Asp-His triad and only accepts Dtetrapeptides, containing the D-isomer of alanine at the fourth position, as substrate $[17,40]$. Loss of function of DacA, DacB or both enzymes resulted in severe defects in cell morphology and division as expressed by decreased pneumococcal growth and yield, rounded and less dense cells suggesting enhanced autolysis, and division asymmetry. In addition, $\Delta d a c$ mutants showed an increased susceptibility to the antibiotic vancomycin, which binds to the terminal D-Ala-D-Ala dipeptide of Lipid II [17, 52]. Interestingly, deficiency in lipoprotein diacylglyceryl transferase Lgt did not affect L,D-carboxypeptidase activity of $\mathrm{DacB}$, indicating that attachment of the lipid anchor to the DacB-preprolipoprotein is not essential for enzymatic activity. Importantly, it has been suggested that due to reduced 
integrity of the peptidoglycan network in pneumococcal $\Delta d a c$ mutants an improper sortasedependent anchoring of surface-proteins, e.g. pneumococcal adherence and virulence factor $B(P a v B)$, might result in the diminished pneumococcal adherence to human lung epithelial cells in vitro. In addition, impaired cell division has been shown to enhance uptake and to reduce survival of pneumococci in professional phagocytes, negatively affecting the success of $S$. pneumoniae to cause infection. Likewise, attenuation of $\Delta d a c$ mutants has been demonstrated in vivo in a mouse model of acute pneumonia. While DacA had only minor effects on sepsis development, $\triangle d a c B$ and double $\triangle$ dacA $\triangle$ dacB-mutants were severely impaired in their ability to spread from the nasopharynx into the bloodstream (Table 1) [17]. In conclusion, the importance of DacA and DacB for peptidoglycan architecture and bacterial shape as well as the close connection between PGN metabolism and virulence of $S$. pneumoniae could provide new opportunities for the development of novel drugs and vaccines.

\subsubsection{Two thiroredoxin-lipoproteins as key factors for the extracellular antioxidant defence in pneumococci}

Resistance to oxidative stress is of utmost importance for $S$. pneumoniae as it ensures successful colonization and subsequent disease development. Reactive oxygen species (ROS) such as superoxide anion, hydrogen peroxide, and hydroxyl radicals, are produced from oxygen and known to irreversibly damage many types of cellular macromolecules. Exogenous sources of ROS are professional phagocytes (oxidative burst) and other lactic acid bacteria in the nasopharynx. In addition, pneumococci endogenously produce up to millimolar concentrations of hydrogen peroxide by the pyruvate oxidase SpxB. High local peroxide concentrations provide a selective advantage for $S$. pneumoniae against competing organisms in the oxygen-rich upper respiratory tract and contribute to pneumococcal pathogenesis due to DNA damage-induced cell death in airway epithelial cells [56-58]. Although lacking catalase, the major peroxide-degrading enzyme in all aerobic organisms, pneumococci are able to survive in oxidative environments by both detoxifying oxygen and ROS and repairing oxidative damage. Scavenging by glutathione as well as detoxification by superoxide dismutase (SodA), NADH oxidase (Nox), alkyl hydroperoxidase (AhpD), thiol peroxidase (TpxD), and thioredoxin-methionine sulfoxide reductase (Trx-Msr) systems are known resistance mechanisms to intracellular oxidative stress in $S$. pneumoniae [59]. Extracellular protein integrity is maintained by chaperones and proteases such as heatshock-induced serine protease A ( $\mathrm{HtrA}$ ) and Clp ATP-dependent proteases. In addition, the surface-exposed CTM system, consisting of a cytochrome c-type biogenesis protein (CcdA), a thioredoxin-like lipoprotein (TIpA), and a methionine sulfoxide reductase A/B protein (SpMsrAB), has been implicated in extracellular ROS resistance. It was hypothesized that 
TIpA (renamed to Etrx1 by Saleh et al.), reduced by CcdA, shuttles electrons to SpMsrAB which can subsequently reduce oxidized methionine residues (MetSO) in damaged surfaceexposed proteins, thereby restoring their functional capacities $[21,59,60]$. Recently, Saleh et al. expanded our knowledge on the composition of the pneumococcal CTM system as well as its importance for pneumococcal oxidative stress resistance and pathogenesis in vivo [21]. In addition to the previously described CTM operon, a second incomplete CTM operon has been identified to be surface-exposed in S. pneumoniae D39. Therefore, components of the "classical" CTM were renamed to CcdA1, Extracellular thioredoxin protein (Etrx) 1 (formerly TlpA), and SpMsrAB2 (to distinguish it from the homologous intracellular SpMsrAB1 protein). The incomplete CTM operon consists of a ccdA-like gene, designated $\operatorname{ccd} A 2$, and a paralogous gene to etrx1, assigned as etrx2, but lacks an msrAB-like gene. Both Etrx1 and Etrx2 are surface-exposed lipoproteins and, despite low sequence identity, share significant structural features common to members of the thioredoxin family: a threelayer $\alpha / \beta / \alpha$ sandwich containing seven $\beta$-strands flanked by five $\alpha$-helices and the invariant CXXC motif, whose two cysteine residues shuttle between the oxidized (disulfide) and reduced (dithiol) states (Table 1) [21, 61].

Several observations support the conclusion that, albeit functionally redundant, both Etrx proteins are required for efficient regeneration of oxidized SpMsrAB2: i) genetic deletion of both Etrx lipoproteins renders $S$. pneumoniae susceptible to extracellular peroxide stress and enhances phagocytic killing of pneumococci in vitro, ii) loss of both Etrx proteins significantly reduced nasopharyngeal carriage and dissemination of pneumococci into the lower respiratory tract and bloodstream in mouse models of infection (Table 1), and iii) relevant structural differences in the active sites of Etrx1 and Etrx2, different redox states and potentials as well as varying kinetic activities of SpMsrA2/B2-Etrx1/2 complexes suggest that Etrx1 preferentially reduces the SpMsrA2 domain while Etrx2 can shuttle electrons to SpMsrA2 and, with lower efficiency, to SpMsrB2. Therefore, a model for two CcdA-EtrxSpMsrAB2 electron pathways has been proposed in which an electron transport chain initiates with the intracellular NADPH-Trx system, passes through the cytoplasmic membrane via either CcdA1 or CcdA2, which reduce either Etrx1 or Etrx2, continues with reduction of SpMsrAB2 and terminates with MetSO in ROS-damaged surface-exposed proteins as final electron acceptor [21].

\subsection{Functions of Pneumococcal $A B C$ Transporter Lipoproteins}

The ATP-binding cassette $(A B C)$ transporter systems are universally distributed among eukaryotes and prokaryotes. They play critical roles in bacterial physiology as they import essential nutrients and export toxic molecules (e.g. bacteriocins and antibiotics) and pheromones. $\mathrm{ABC}$ transporter systems are composed of two intracellular nucleotide-binding 
domains that hydrolyse ATP for energy and two transmembrane domains transporting molecules and ions across the cytoplasmic membrane, also referred to as permeases. $A B C$ importer systems additionally possess an extracellular substrate-binding protein (SBP), which determines substrate specificity and is often a lipoprotein in both Gram-negative and Gram-positive bacteria [62]. Up to 30 ABC transporter-associated lipoproteins have been predicted in $S$. pneumoniae and for some, their surface-localisation and impact on bacterial fitness and virulence has been experimentally confirmed or implicated by large-scale genomic analyses. These include $A B C$ transporter lipoproteins for acquisition of metal ions (e.g. PsaA; AdcA and AdcAll; PiaA, PiuA and PitA), amino acids and short peptides (MetQ, GInH; AmiA-AliA/AliB), sugars (MalX), and inorganic compounds (i.e. PstS) (Table 2) [15, 32, 63-65]. For instance, the three iron-uptake $A B C$ transporter systems Pia, Piu, and Pit are required for bacterial growth and virulence in both pulmonary and systemic models of infection, albeit loss of PiaA, the iron-binding SBP of Pia, has stronger effects on pneumococcal phenotype than loss of the iron-binding lipoproteins PiuA and PitA (Table 2) [65-67]. Furthermore, an additional iron-uptake ABC transporter lipoprotein (SPD_1609) is encoded in the pneumococcal genome and expressed in $\Delta p i a A / \Delta p i u A / \Delta p i t A$ triple mutants in iron-repleted medium but has not yet been investigated in detail [15, 68,69]. Acquisition of metal ions is essential for survival of $S$. pneumoniae in their infected host. Therefore, two important interconnected pneumococcal metal ion uptake systems are discussed in more detail below.

\subsubsection{From tolerance to toxicity: Importance of manganese and zinc homeostasis on pneumococcal fitness and virulence}

Manganese is one of the essential micronutrients for the growth and survival of pneumococci in the human host as it is a cofactor for pneumococcal superoxide dismutase (SodA), an enzyme which detoxifies endogenously produced hydrogen peroxide. Pneumococcal uptake of $\mathrm{Mn}$ (II) ions is mediated by the PsaBCA transporter consisting of PsaA as substrate-binding lipoprotein, PsaC as permease, and PsaB as ATP-binding protein (Table 2; Figure 3). Expression of the psaBCA operon is repressed by PsaR in presence of high $\mathrm{Mn}(\mathrm{II})$ concentrations and activated by the two-component system TCS04 [70, 71]. PsaA is an ubiquitously expressed $35-\mathrm{kDa}$ lipoprotein belonging to cluster $A-I$ of bacterial $A B C$ transporters. In crystals, the protein folds into a two-lobed structure that consists of an $\mathrm{N}$ - and C-terminal domain providing the metal-binding site and linked by a rigid $\alpha$-helix which has been proposed to restrict conformational flexibility [72]. Very recently, conformational states of metal-free PsaA in solution have been resolved showing that $i)$ the C-terminal lobe is more flexible than the $\mathrm{N}$-terminal lobe, providing additional proof for the importance of the $\mathrm{C}$ terminal lobe as recognition site for the permease PsaC, ii) the $\alpha$-helical hinge between the 
two lobes allows a greater conformational flexibility important for ligand binding, and iii) the metal-binding site is larger and more solvent exposed than indicated by crystallography and in silico simulations [73]. PsaA was shown to bind both manganese and zinc. Although PsaA kinetically prefers $\mathrm{Mn}(\mathrm{II})$ to $\mathrm{Zn}(\mathrm{II})$, zinc bound to PsaA induces a higher thermal stability of the protein complex, therefore remains bound to the lipoprotein and is not released to the Psa permease $[74,75]$. If the $\mathrm{Zn}(\mathrm{II})$ to $\mathrm{Mn}(\mathrm{II})$ ratio in the respective host niche exceeds a critical level (Zn(II):Mn(II) of 50-100:1), zinc competes with Mn(II) for binding to PsaA which leads to an intracellular depletion of $\mathrm{Mn}(\mathrm{II})$ and results in phenotypes similar to $\Delta p s a A$ knockout mutants. Pneumococci deficient in PsaA have a significant requirement for additional Mn(II) for growth and competence and are highly susceptible to oxidative stress and greatly decreased virulence in local and systemic models of infection (Table 2) [74]. In addition, $\triangle p s a A$ knockout strains display reduced adherence to human pneumocytes and E-cadherin has been suggested as eukaryotic cell receptor. However, a direct role for PsaA as an adhesin has not yet been conclusively clarified (Table 2) [20, 76].

\subsubsection{Zinc acquisition via AdcA and AdcAll is critical for pneumococcal pathogenesis}

Zinc belongs to the essential trace metals for pneumococci and is an important cofactor for basic housekeeping metalloenzymes and transcription factors. However, zinc is toxic at high concentrations, for example when released from damaged or apoptotic cells during inflammation or bacterial infection, in part due to outcompeting Mn(II) for binding to PsaA as discussed above [77]. Therefore, the balance between zinc and manganese homeostasis are crucial for survival and virulence of $S$. pneumoniae. Pneumococcal $\mathrm{Zn}$ (II) acquisition occurs via AdcA and AdcAll lipoproteins and is supported by Polyhistidine triad (Pht) family proteins (Table 2; Figure 3) [78, 79]. The adcRCBA ABC transporter operon encodes for the transcriptional repressor AdcR, the zinc-binding SBP AdcA, the AdcB permease and AdcC ATPase [80]. In contrast, AdcAll is not encoded in a classical ABC transporter operon. In fact, the adcAll gene is part of a long transcript together with phtD, encoding for the Pht protein D, downstream of adcAll [81]. The pneumococcal lipoproteins AdcA and AdcAll share high structural similarities to PsaA and belong therefore also to the cluster A-I SBPs [78, 81]. In contrast to PsaA, which was shown to bind both $\mathrm{Mn}(\mathrm{II})$ and $\mathrm{Zn}(\mathrm{II})$, AdcA and AdcAll demonstrate absolute substrate-specificity for zinc [78, 82]. AdcAll transfers bound $\mathrm{Zn}$ (II) to the AdcB permease indicating that both AdcA and AdcAll use the same permease/ATPase-system to transport $\mathrm{Zn}(\mathrm{II})$ into the cell. AdcA and AdcAll are individually redundant in zinc acquisition, and $\triangle a d c A$ and $\triangle a d c A l l$ single mutants show only modest attenuation in virulence in mouse models of colonisation and infection. However, combined loss of both zinc-binding proteins significantly impaired growth in artificial media, in bronchoalveolar lavage fluid, and human serum, affected pneumococcal cell division and 
competence, as well as completely abolishing virulence (Table 2) [78, 82]. Interestingly, in contrast to AdcA, AdcAll does not possess structural features allowing a direct sequestration of $\mathrm{Zn}(\mathrm{II})$ indicating that accessory molecular interactions are needed for AdcAll function and zinc homeostasis. Indeed, the four Pht proteins, PhtA, PhtB, PhtD and PhtE, have been shown to collectively aid in $\mathrm{Zn}(\mathrm{II})$ acquisition via AdcAll, though the molecular mechanism, either by a direct physical interaction of AdcAll and Pht or enrichment of local zinc concentrations by $\mathrm{Pht}$, is still elusive [79]. AdcR transcriptionally represses expression of the adcRCBA operon and the adcAll/phtD operon. Computational analysis revealed a variable number of AdcR-binding sites upstream of adcRCBA, adcAll/phtD and, interestingly, also upstream of $p h t E$, which is encoded contiguous to $p h t D$. Hence, it has been suggested that a single AdcR-binding site upstream of adcR permits autoregulation of the adcRCBA operon and provides a basal supply of $\mathrm{Zn}(\mathrm{II})$ in zinc-rich host environments, while two binding sites upstream of $a d c A l l / p h t D$ and three AdcR-binding sites upstream of phtE enable upregulation of AdcAll and Pht proteins to adapt to zinc limiting conditions [78]. Therefore, niche-specific adaptations to zinc and manganese availability are likely to maintain fitness and contribute to pneumococcal virulence.

\subsubsection{The pneumococcal nucleoside receptor $A$ interferes with virulence}

Facing the dramatically increasing resistance of $S$. pneumoniae to antibiotics, the replacement of vaccine serotypes by non-vaccine serotypes, and the immense individual costs for each serotype to be included in a glycoconjugate vaccine, development of a serotype-independent, protein-based vaccine is an attractive alternative. Several pneumococcal surface-associated proteins, including PsaA, PiaA and PiuA, have been identified as vaccine candidates and already tested in mouse and human, though long-term effects aren't yet known. However, combination of different pneumococcal proteins in one vaccine formulation tends to be more effective in establishment of protection against disease in mouse models of infection and ongoing research is striving to discover novel pneumococcal proteins as vaccine candidates [83, 84]. Recently, SP_0845 has been proposed as potential vaccine antigen identified by affinity and gel-free proteomic approaches $[15,85]$. SP_0845 is the substrate-binding protein of the sole carbohydrate uptake $A B C$ transporter superfamily 2 (CUT2) in $S$. pneumoniae and encoded in an eightgene operon also containing the corresponding ATPase and two permeases predicted to function as heterodimers [86]. Since SP_0845 exhibits $70 \%$ identity to the orthologue in S. mutans and is similarly involved in uptake and metabolism of ribonucleosides preferentially containing cytidine, uridine, and guanosine, it has been designated as purine nucleoside receptor $\mathrm{A}$ (PnrA, in the literature also referred to as TmpC) (Table 2) [85, 87]. PnrA has been confirmed as conserved, surface-exposed lipoprotein accessible to (protective) 
antibodies in both encapsulated and nonencapsulated pneumococci (Figure 3; see also section 3.2.) $[15,85]$. Importantly, deletion of pnrA completely abolished virulence of $S$. pneumoniae type 2 strain D39 and type 4 strain TIGR4 [85].

\subsubsection{Strain-dependent influence of MetQ on pneumococcal fitness and virulence}

In all living organisms, methionine is essential for the biosynthesis of proteins, phospholipids and nucleic acids. However, this amino acid is very rare in mammalian physiological fluids and hardly available to bacteria in their natural host niche. Therefore, S. pneumoniae possesses a methionine $A B C$ uptake transporter that has been recently identified as surfaceexposed by proteomic analysis [15, 88]. MetQ is the substrate-binding lipoprotein of the MetQNP ABC transporter system, including the ATP-binding protein MetN and the permease MetP (Table 2; Figure 3). MetQ exhibits high affinity for L-methionine but also binds, albeit with significantly lower affinity, D-methionine and the non-proteinogenic amino acid DLhomocysteine. Loss of function of MetQ impaired growth in both chemically defined medium and human blood indicating that methionine uptake via MetQ is crucial for pneumococcal fitness [88]. In signature-tagged mutagenesis screens, MetQ has been identified as essential for pneumococcal nasopharyngeal colonisation and invasive disease [89, 90]. Indeed, MetQ has been shown to contribute to pneumococcal colonization and virulence, though in a strain-specific manner. In a mouse model of mixed infection with a pneumococcal serotype 3 strain and its respective $\Delta m e t Q$ mutant, deletion of $m e t Q$ had no impact on nasopharyngeal colonisation and two opposing results have been reported on the competitive ability of the $\triangle m e t Q$ strain against the wild-type in pulmonary and systemic mouse infection models [88, 91]. Interestingly, when administered separately, the $\Delta m e t Q$ and wild-type strain showed a similar virulence pattern in a murine pneumonia model [88]. In contrast, deletion of metQ in S. pneumoniae serotype 2 strain D39 significantly attenuated virulence in a mouse model of acute pneumonia as monitored real time with bioluminescent imaging (Table 2; Figure 3) [92]. Moreover, vaccination with recombinant MetQ failed in a first attempt to prevent systemic pneumococcal infection after heterologous challenge [88]. Hence, extensive studies are required to obtain a holistic understanding of the impact of MetQ on pneumococcal virulence and to conclusively evaluate the applicability of MetQ in future protein-based pneumococcal vaccines.

\section{Immunogenicity and Protective Potential of Pneumococcal Lipoproteins}

\subsection{Inflammatory Immune Responses to Pneumococcal Lipoproteins}

S. pneumoniae infections are characteristically associated with inflammation [93], with a strong acute phase response, rapid leukocyte recruitment to the site of infection, and 
endothelial / epithelial barrier breakdown. S. pneumoniae causes inflammation partly through recognition of bacterial ligands by host cell surface Toll-like receptors (TLR), with mouse and human data both demonstrating that genetic deficiencies of TLRs or their signalling proteins increases susceptibility to pneumococcal infections [94-98]. TLR2 seems to be the dominant TLR driving responses to $S$. pneumoniae, especially macrophage production of proinflammatory cytokines such as TNFa and IL-6 [22, 99-102]. TLR2 has been shown to be important for inflammation and control of infection in mouse models of infection [99-101], and indirectly increases inflammatory responses to the pneumococcal toxin pneumolysin [103]. In addition, TLR2 responses are required for the development of adequate cellular and humoral adaptive immune responses to $S$. pneumoniae [104, 105].

Lipoproteins are known TLR2 agonists, and recent data obtained using an $\Delta / g t$ mutant has demonstrated that the complete TLR2 response to $S$. pneumoniae requires bacterial lipoproteins [22]. Infection of macrophages with the pneumococcal lipoprotein deficient $\Delta / g t$ mutant strain resulted in reduced activation of the pro-inflammatory transcriptional factor NFKB, and lower levels of pro-inflammatory cytokine release; cytokine levels were also lower in samples recovered from a murine model of early pneumonia for animals infected with the $\Delta / g t$ mutant compared to those infected with the wild type strain. The differences in inflammatory responses between wild-type and the Lgt deficient strains were not due to indirect effects of loss of lipoproteins on bacterial growth or cell wall structure, and were lost when bacteria were incubated with TLR2 deficient macrophages [22]. There were striking but selective differences in human macrophage transcriptional responses between the $\Delta / g t$ mutant and wild-type $S$. pneumoniae strains. Although infection with S. pneumoniae caused up-regulation of over 900 macrophages genes, only a small proportion of these had significantly greater expression in response to the wild-type strain compared to the $\Delta / g t$ strain. However, the genes showing stronger responses to wild-type bacteria compared to the $\Delta / g t$ mutant included many important pro-inflammatory proteins, and in general were also the genes showing the greatest up-regulation in response to wild type S. pneumoniae or to the TLR2 agonist Pam2CSK4 [22]. Hence, the dominant macrophage transcriptional responses to $S$. pneumoniae are largely TLR2-dependent and usually require the presence of lipoproteins for maximal stimulation.

These results demonstrated that pneumococcal lipoproteins are major contributors (probably the dominant ligand) to the macrophage TLR2-mediated inflammatory response. The $S$. pneumoniae cell wall is highly pro-inflammatory, and it was previously suggested that PGN and LTA are the major pneumococcal TLR2 agonists [106-108]. However, cell-wall dependent inflammation is also mediated by nucleotide-binding oligomerization domain (NOD) recognition of PGN, and purified pneumococcal LTA does not activate a TLR2 reporter cell $[41,109,110]$. Taken together the data suggest that TLR2 dependent 
inflammatory responses to the pneumococcal cell wall are largely driven by lipoprotein contamination rather than TLR2 recognition of PGN or LTA, a similar situation to that described for $S$. aureus [111, 112]. Importantly, the pattern of human inflammatory cytokine responses to the $\Delta / g t$ mutant strain were similar to those seen for subjects with IRAK-4 deficiency, a rare genetic defect of the TLR activation signalling pathway that causes greatly increased susceptibility to $S$. pneumoniae infection [96, 97]. This suggests that lipoproteins are important ligands driving IRAK-4 dependent inflammatory responses and therefore protective immunity in children.

Several important questions remain unanswered about lipoprotein-dependent TLR2 responses. Firstly, how do TLR2 receptors interact with $S$. pneumoniae lipoproteins when the lipoprotein moiety is at the cell membrane level and is separated by both the cell wall and the capsule from interactions with host cells? TLR2 activation occurs in response to live bacteria [22], but it is difficult to understand how lipoproteins can interact with TLR2 receptors unless they are released from the cell membrane to some extent, or TLR2 receptors penetrate through the pneumococcal capsule and cell wall. A related question is whether S. pneumoniae capsular serotype affects TLR2 / lipoprotein interactions, thereby causing differences in inflammatory responses between different strains and perhaps influencing the clinical phenotypes associated with capsular serotype. Another important question is which lipoproteins are the most dominant in generating the TLR2 response? TLR2 receptors could respond to all the pneumococcal lipoproteins, in which case the most common will dominate the inflammatory response (e.g. PsaA), or to a specific subset that might not necessarily include the most abundant lipoproteins. Finally, the relative roles and potentially synergistic interactions of TLR2 induced responses with other $S$. pneumoniae pro-inflammatory mechanisms such as NOD or in response to pneumolysin need further exploration [103, 109, 110]. A fuller understanding of TLR2 / lipoprotein interactions and how they affect inflammatory responses during $S$. pneumoniae infection may reveal potential novel therapeutic mechanisms for immunomodulation aiming to improve patient outcomes.

\subsection{Pneumococcal Lipoproteins as Next-Generation Vaccine Candidates or drug targets}

Two different types of vaccines are currently available to combat pneumococcal infections: the 23-valent polysaccharide vaccine PPV-23 and the 7-, 10- or 13-valent pneumococcal polysaccharide conjugate vaccines (PCV-7, -10, -13). Despite their efficacy and potential impact, there are some limitations to the current pneumococcal vaccines, including the need for multiple doses, the lack of protection against non-vaccine serotypes and, particularly for developing countries, the cost $[113,114]$. In the last two decades, efforts have been increasingly directed to overcome these shortcomings by finding new generation 
pneumococcal vaccines, which provide serotype-independent protection against invasive as well as non-invasive pneumococcal disease [83, 115-117].

Various pneumococcal proteins have been studied as potential vaccine candidates. Especially surface-exposed proteins getting in contact with the extracellular milieu in the host and are therefore likely accessible for antibodies to generate an effective immune response, are the most promising candidates for a protein-based vaccine. Importantly, these proteins have to be highly immunogenic, conserved among pneumococcal serotypes and able to cause both humoral and cellular immune responses required for protection against $S$. pneumoniae infection [118]. The best studied potential vaccine candidate among the surfacelocalized lipoproteins is the Pneumococcal surface adhesin A (PsaA) [119]. PsaA is a highly immunogenic protein as antibody responses to PsaA have been described in children and were related to pneumococcal exposure [120-123]. Moreover, PsaA is highly conserved among almost all pneumococcal serotypes [124, 125]. In both passive and active immunization studies, PsaA failed to confer protection against systemic infection, which was reasoned to be due to low accessibility of PsaA for circulating host antibodies [126, 127]. In contrast, in several studies the protective efficacy of PsaA against pneumococcal carriage has been demonstrated. Mice immunized intranasally with PsaA and Cholera toxin B (CTB) subunit, as mucosal adjuvant, showed significantly reduced bacterial loads in the nasopharynx. This protection was even higher when a combination of PsaA together with PspA was used [128]. The best results in protective efficacy could be achieved for using PsaA in combination with other antigens as shown in both intraperitoneal and intranasal challenge models [129-131].

Preclinical investigations demonstrated that protection against pneumococcal carriage is mediated by a $T_{H} 17$-dependent immune response when immunizing mice with a heat killed whole-cell vaccine. High levels of IL-17 in the blood were correlated with nondetectable numbers of pneumococci in the nasopharynx of mice [105, 132]. A nasal formulation containing PsaA, pneumococcal surface protein C (PspC, also designated as $\mathrm{CbpA}$ ), and detoxified pneumolysin toxoid (PdT) in the presence of cholera toxin elicited the secretion of IL-17 by CD4+T cells in mice and protected against nasal colonization [131]. Lu and colleagues also tested a conjugate vaccine based on a PsaA-PdT fusion protein and the cell-wall polysaccharide by the nasal route. This vaccine could also stimulate IL-17 responses and high antibody production against the three antigens. Protection could be finally shown in the nasal colonization and the fatal aspiration pneumonia model [133]. Beside immunization with recombinant protein, a live attenuated Salmonella vaccine strain heterologously expressing PsaA on its surface was used to analyse its protective potential. $\mathrm{BALB} / \mathrm{c}$ or $\mathrm{C57BL} / 6$ mice vaccinated either orally or intranasally exhibited a significant reduction in colonization of nasopharyngeal tissues after intranasal challenge with $S$. 
pneumoniae serotype $6 \mathrm{~B}$ and 23 . In contrast, none of the vaccine constructs provided protection against intraperitoneal challenge with $S$. pneumoniae serotype 3 [134]. Moreover, three different lactic acid bacilli (LAB) strains expressing surface-attached PsaA were used to immunize mice intranasally with following colonization challenge with $S$. pneumoniae serotype 6B. All lactobacilli-based vaccines except the recombinant $L$. lactis strain significantly reduced pneumococcal nasal colonization [135].

Besides PsaA, other surface-localized lipoproteins of pneumococci have been investigated regarding their protective efficacy as vaccine antigens. In 2000, Overweg et al. isolated a pool of hydrophobic, surface-associated proteins of $S$. pneumoniae and analyzed the opsonophagocytic activity of hyperimmune serum raised against this protein fraction. The opsonophagocytic activity was serotype-independent and mainly caused by three proteins: choline-binding protein PspA, and the two lipoproteins PpmA and AmiA. Thus, they concluded that these proteins might have potential to elicit protective immune responses as opsonophagocytic activity correlated with in vivo protection [136]. Later, by analysis of acute and convalescent phase sera from young children ( $<2$ years) related to otitis media infection, it was shown that both lipoproteins PpmA and SIrA are immunogenic and elicit antibody responses early in life [137]. This was confirmed in another study where the association between specific antibodies against pneumococcal virulence proteins, colonization, and respiratory tract infections (RTI) was assessed in young children. Increased levels of IgG could be identified for e.g. PsaA, PpmA and SIrA, which were furthermore associated with a decreased number of RTIs [138]. Moreover, the Gram-positive Enhancer Matrix (GEM)based vaccine system was used to display PpmA, SIrA and IgA1 protease (IgA1p) on the surface of a non-recombinant, killed L. lactis-derived strain [139]. Significant protection against fatal pneumococcal pneumonia could be shown in mice following an intranasal immunization with the SIrA-IgA1p or trivalent vaccine combinations without any additional adjuvants [140].

The two iron uptake $A B C$ transporter substrate-binding lipoproteins PiuA and PiaA were investigated in a systemic infection model with $S$. pneumoniae D39. Recombinant PiuA and PiaA in conjunction with Alum as adjuvant were administered intraperitoneally to mice followed by pneumococcal challenge. Immunized mice showed a significant increase of survival time while this effect augmented when both antigens were used together [141]. In addition, mucosal immunization of mice with PiuA and PiaA elicited specific antibody responses in serum and respiratory secretions, and protected against intranasal challenge with S. pneumoniae [142]. Mice were also protected after passive immunization with antisera raised against these proteins and following systemic pneumococcal challenge leading to the assumption that protection is antibody-mediated [141]. Indeed, anti-PiaA and anti-PiuA antibodies increase complement-independent and -dependent opsonophagocytosis of 
different pneumococcal serotypes. As these antibodies did not alter growth of $S$. pneumoniae in cation-depleted medium, it was suggested that vaccination with PiaA and PiuA protects against $S$. pneumoniae infection by inducing antibodies that promote bacterial opsonophagocytosis rather than inhibiting iron transport [142].

The highly conserved putative nucleoside $A B C$ transporter binding protein PnrA (SP_0845 in S. pneumoniae TIGR4) was shown to be accessible to antibodies in encapsulated pneumococcal strains. In addition, subcutaneous immunization with recombinant PnrA induced high titers and functional antibodies in mice while these sera were able to promote killing of encapsulated pneumococcal strains in a blood bactericidal assay. Mice immunized with PnrA were protected against heterologous challenge with serotype 3 and serotype 14 strains in a murine sepsis model (Table 2) [85]. Thus, PnrA might me a suitable candidate for future vaccines.

As IL-17-secreting CD4 ${ }^{+} T$ cells $\left(T_{H} 17\right)$ mediate resistance to mucosal colonization by multiple pathogens including $S$. pneumoniae, an expression library containing $>96 \%$ of predicted pneumococcal proteins was screened. Thereby, antigens recognized by $T_{H} 17$ cells from mice immune to pneumococcal colonization were identified. Two lipoproteins, the maltose/maltodextrin $A B C$ transporter binding protein MalX and the putative polar amino acid ABC transporter binding protein SP_0148, were among the identified antigens which provided protection from pneumococcal colonization [143]. As a lot of pneumococcal lipoproteins have already been identified to elicit protective immune responses, they are promising candidates for innovative and serotype-independent vaccines in the future.

The most prominent pneumococcal protein candidates investigated in phase I/II clinical trials include PhtD, the choline-binding protein a (PcpA) and the highly detoxified pneumolysin mutant (dPlyD1). Vaccine formulations containing these proteins were safe and immunogenic, and PhtD could also trigger production of functional post-immune human antibodies [144-146]. Another multivalent recombinant subunit protein vaccine in a phase I trial is IC47 (Intercell AG, Austria, NCT00873431), which contains the highly conserved lipoprotein pneumococcal surface adhesion A (PsaA), serine/ threonine protein kinase (StkP) and a putative murine hydrolase (PcsB). It was shown to be safe and induced protective antibodies against all three proteins in a dose-dependent manner [84]. Despite these promising outcomes, not any protein-based vaccine has reached phase III clinical trials yet, not to mention being on the way of licensing. So far, only polysaccharide-protein conjugate vaccines (PCVs) and the polysaccharide vaccine PPV23 are commercially available and recommended by the World Health Organization (WHO) [147]. However, both have major shortcomings like serotype replacement, limited serotype coverage, and high costs caused by complex manufacturing processes [84]. For this reason, development of new generation 
vaccines, which can provide serotype-independent protection against pneumococcal infections and are affordable for especially developing countries, is of highest concern.

\section{Conclusions and Perspectives}

Lipoproteins represent an important class of cell envelope proteins crucial for pneumococcal fitness, colonization and pathogenesis. Loss of function of either Lgt or Lsp, essential for lipoprotein maturation, strongly affects in vitro bacterial fitness and pneumococcal virulence in experimental mouse models of infection. The detailed analysis of lipoprotein functions indicated their variety regarding their function in cellular and pathogen-host functions. Strikingly, lipoproteins, irrespective whether they are part of an ABC transporter or "classical" lipoproteins, are highly conserved among pneumococci and immunogenic. These lipoproteins affect further both the innate and acquired immune system via TLR2 signalling or by stimulating the production of protective antibodies. Thus, several pneumococcal lipoproteins have been extensively evaluated as vaccine candidates. In addition, the essentiality of lipoprotein maturation enzymes for the survival and virulence of $S$. pneumoniae supports them as attractive and broad spectrum antimicrobial targets. 


\section{References}

[1] Henriques-Normark, B., Tuomanen, E.I. (2013). The pneumococcus: epidemiology, microbiology, and pathogenesis. Cold Spring Harb Perspect Med. 3.

[2] Song, J.Y., Nahm, M.H., Moseley, M.A. (2013). Clinical implications of pneumococcal serotypes: invasive disease potential, clinical presentations, and antibiotic resistance. J Korean Med Sci. 28, 415.

[3] Simell, B., Auranen, K., Kayhty, H., Goldblatt, D., Dagan, R., O'Brien, K.L., et al. (2012). The fundamental link between pneumococcal carriage and disease. Expert Rev Vaccines. 11, 841-55.

[4] Voss, S., Gamez, G., Hammerschmidt, S. (2012). Impact of pneumococcal microbial surface components recognizing adhesive matrix molecules on colonization. Mol Oral Microbiol. 27, 246-56.

[5] Kadioglu, A., Weiser, J.N., Paton, J.C., Andrew, P.W. (2008). The role of Streptococcus pneumoniae virulence factors in host respiratory colonization and disease. Nat Rev Microbiol. 6, 288301.

[6] Perez-Dorado, I., Galan-Bartual, S., Hermoso, J.A. (2012). Pneumococcal surface proteins: when the whole is greater than the sum of its parts. Mol Oral Microbiol. 27, 221-45.

[7] Geno, K.A., Gilbert, G.L., Song, J.Y., Skovsted, I.C., Klugman, K.P., Jones, C., et al. (2015). Pneumococcal Capsules and Their Types: Past, Present, and Future. Clin Microbiol Rev. 28, 871-99.

[8] Hyams, C., Camberlein, E., Cohen, J.M., Bax, K., Brown, J.S. (2010). The Streptococcus pneumoniae capsule inhibits complement activity and neutrophil phagocytosis by multiple mechanisms. Infect Immun. 78, 704-15.

[9] Nelson, A.L., Roche, A.M., Gould, J.M., Chim, K., Ratner, A.J., Weiser, J.N. (2007). Capsule enhances pneumococcal colonization by limiting mucus-mediated clearance. Infect Immun. 75, 83-90.

[10] Wartha, F., Beiter, K., Albiger, B., Fernebro, J., Zychlinsky, A., Normark, S., et al. (2007). Capsule and D-alanylated lipoteichoic acids protect Streptococcus pneumoniae against neutrophil extracellular traps. Cell Microbiol. 9, 1162-71.

[11] Hammerschmidt, S., Wolff, S., Hocke, A., Rosseau, S., Muller, E., Rohde, M. (2005). Illustration of pneumococcal polysaccharide capsule during adherence and invasion of epithelial cells. Infect Immun. $73,4653-67$.

[12] Kim, J.O., Weiser, J.N. (1998). Association of intrastrain phase variation in quantity of capsular polysaccharide and teichoic acid with the virulence of Streptococcus pneumoniae. J Infect Dis. 177, 368-77.

[13] Weiser, J.N., Kapoor, M. (1999). Effect of intrastrain variation in the amount of capsular polysaccharide on genetic transformation of Streptococcus pneumoniae: implications for virulence studies of encapsulated strains. Infect Immun. 67, 3690-2.

[14] Babu, M.M., Priya, M.L., Selvan, A.T., Madera, M., Gough, J., Aravind, L., et al. (2006). A database of bacterial lipoproteins (DOLOP) with functional assignments to predicted lipoproteins. $J$ Bacteriol. 188, 2761-73.

[15] Pribyl, T., Moche, M., Dreisbach, A., Bijlsma, J.J., Saleh, M., Abdullah, M.R., et al. (2014). Influence of impaired lipoprotein biogenesis on surface and exoproteome of Streptococcus pneumoniae. J Proteome Res. 13, 650-67.

[16] Kovacs-Simon, A., Titball, R.W., Michell, S.L. (2011). Lipoproteins of bacterial pathogens. Infect Immun. 79, 548-61.

[17] Abdullah, M.R., Gutierrez-Fernandez, J., Pribyl, T., Gisch, N., Saleh, M., Rohde, M., et al. (2014). Structure of the pneumococcal I,d-carboxypeptidase DacB and pathophysiological effects of disabled cell wall hydrolases DacA and DacB. Mol Microbiol. 93, 1183-206.

[18] Cron, L.E., Bootsma, H.J., Noske, N., Burghout, P., Hammerschmidt, S., Hermans, P.W. (2009). Surface-associated lipoprotein PpmA of Streptococcus pneumoniae is involved in colonization in a strain-specific manner. Microbiology. 155, 2401-10.

[19] Hermans, P.W., Adrian, P.V., Albert, C., Estevao, S., Hoogenboezem, T., Luijendijk, I.H., et al. (2006). The streptococcal lipoprotein rotamase A (SIrA) is a functional peptidyl-prolyl isomerase involved in pneumococcal colonization. J Biol Chem. 281, 968-76.

[20] Rajam, G., Anderton, J.M., Carlone, G.M., Sampson, J.S., Ades, E.W. (2008). Pneumococcal surface adhesin A (PsaA): a review. Crit Rev Microbiol. 34, 163-73.

[21] Saleh, M., Bartual, S.G., Abdullah, M.R., Jensch, I., Asmat, T.M., Petruschka, L., et al. (2013). Molecular architecture of Streptococcus pneumoniae surface thioredoxin-fold lipoproteins crucial for extracellular oxidative stress resistance and maintenance of virulence. EMBO Mol Med. 5, 1852-70.

[22] Tomlinson, G., Chimalapati, S., Pollard, T., Lapp, T., Cohen, J., Camberlein, E., et al. (2014). TLR-mediated inflammatory responses to Streptococcus pneumoniae are highly dependent on surface expression of bacterial lipoproteins. J Immunol. 193, 3736-45. 
[23] Zhang, Q., Bagrade, L., Clarke, E., Paton, J.C., Nunez, D.A., Finn, A. (2010). Bacterial lipoproteins differentially regulate human primary and memory $C D 4+T$ and $B$ cell responses to pneumococcal protein antigens through Toll-like receptor 2. J Infect Dis. 201, 1753-63.

[24] Moffitt, K., Skoberne, M., Howard, A., Gavrilescu, L.C., Gierahn, T., Munzer, S., et al. (2014). Tolllike receptor 2-dependent protection against pneumococcal carriage by immunization with lipidated pneumococcal proteins. Infect Immun. 82, 2079-86.

[25] Tai, S.S. (2006). Streptococcus pneumoniae protein vaccine candidates: properties, activities and animal studies. Crit Rev Microbiol. 32, 139-53.

[26] Zuckert, W.R. (2014). Secretion of bacterial lipoproteins: through the cytoplasmic membrane, the periplasm and beyond. Biochim Biophys Acta. 1843, 1509-16.

[27] Hutchings, M.I., Palmer, T., Harrington, D.J., Sutcliffe, I.C. (2009). Lipoprotein biogenesis in Gram-positive bacteria: knowing when to hold 'em, knowing when to fold 'em. Trends Microbiol. 17, 13-21.

[28] Okuda, S., Tokuda, H. (2011). Lipoprotein sorting in bacteria. Annu Rev Microbiol. 65, 239-59.

[29] Tam, R., Saier, M.H., Jr. (1993). Structural, functional, and evolutionary relationships among extracellular solute-binding receptors of bacteria. Microbiol Rev. 57, 320-46.

[30] Claverys, J.P. (2001). A new family of high-affinity ABC manganese and zinc permeases. Res Microbiol. 152, 231-43.

[31] Berntsson, R.P., Smits, S.H., Schmitt, L., Slotboom, D.J., Poolman, B. (2010). A structural classification of substrate-binding proteins. FEBS Lett. 584, 2606-17.

[32] Durmort, C., Brown, J.S. (2015). Streptococcus pneumoniae lipoproteins and ABC transporters. In Streptococcus pneumoniae: Molecular mechanisms of host-pathogen interactions (Brown, J.S., Hammerschmidt, S., Orihuela, C., eds), pp. 347-62. ELSEVIER, Amsterdam.

[33] Chimalapati, S., Cohen, J.M., Camberlein, E., MacDonald, N., Durmort, C., Vernet, T., et al. (2012). Effects of deletion of the Streptococcus pneumoniae lipoprotein diacylglyceryl transferase gene lgt on $A B C$ transporter function and on growth in vivo. PLoS One. 7, e41393.

[34] Khandavilli, S., Homer, K.A., Yuste, J., Basavanna, S., Mitchell, T., Brown, J.S. (2008). Maturation of Streptococcus pneumoniae lipoproteins by a type II signal peptidase is required for ABC transporter function and full virulence. Mol Microbiol. 67, 541-57.

[35] Petit, C.M., Brown, J.R., Ingraham, K., Bryant, A.P., Holmes, D.J. (2001). Lipid modification of prelipoproteins is dispensable for growth in vitro but essential for virulence in Streptococcus pneumoniae. FEMS Microbiol Lett. 200, 229-33.

[36] Hamilton, A., Robinson, C., Sutcliffe, I.C., Slater, J., Maskell, D.J., Davis-Poynter, N., et al. (2006). Mutation of the maturase lipoprotein attenuates the virulence of Streptococcus equi to a greater extent than does loss of general lipoprotein lipidation. Infect Immun. 74, 6907-19.

[37] De Greeff, A., Hamilton, A., Sutcliffe, I.C., Buys, H., Van Alphen, L., Smith, H.E. (2003). Lipoprotein signal peptidase of Streptococcus suis serotype 2. Microbiology. 149, 1399-407.

[38] Reglier-Poupet, H., Frehel, C., Dubail, I., Beretti, J.L., Berche, P., Charbit, A., et al. (2003). Maturation of lipoproteins by type II signal peptidase is required for phagosomal escape of Listeria monocytogenes. J Biol Chem. 278, 49469-77.

[39] Zomer, A., Hermans, P.W., Bootsma, H.J. (2015). Non-adhesive surface proteins of Streptococcus pneumoniae. In Streptococcus pneumoniae: Molecular mechanisms of host-pathogen interactions (Brown, J.S., Hammerschmidt, S., Orihuela, C., eds), pp. 231-44. ELSEVIER, Amsterdam.

[40] Hoyland, C.N., Aldridge, C., Cleverley, R.M., Duchene, M.C., Minasov, G., Onopriyenko, O., et al. (2014). Structure of the LdcB LD-carboxypeptidase reveals the molecular basis of peptidoglycan recognition. Structure. 22, 949-60.

[41] Gisch, N., Kohler, T., Ulmer, A.J., Muthing, J., Pribyl, T., Fischer, K., et al. (2013). Structural reevaluation of Streptococcus pneumoniae Lipoteichoic acid and new insights into its immunostimulatory potency. J Biol Chem. 288, 15654-67.

[42] Gisch, N., Peters, K., Zahringer, U., Vollmer, W. (2015). The Pneumococcal Cell Wall. In Streptococcus pneumoniae: Molecular mechanisms of host-pathogen interactions (Brown, J.S., Hammerschmidt, S., Orihuela, C., eds), pp. 145-67. ELSEVIER, Amsterdam.

[43] Mohammadi, T., van Dam, V., Sijbrandi, R., Vernet, T., Zapun, A., Bouhss, A., et al. (2011). Identification of FtsW as a transporter of lipid-linked cell wall precursors across the membrane. EMBO J. 30, 1425-32.

[44] Manat, G., Roure, S., Auger, R., Bouhss, A., Barreteau, H., Mengin-Lecreulx, D., et al. (2014). Deciphering the metabolism of undecaprenyl-phosphate: the bacterial cell-wall unit carrier at the membrane frontier. Microb Drug Resist. 20, 199-214.

[45] Vollmer, W. (2008). Structural variation in the glycan strands of bacterial peptidoglycan. FEMS Microbiol Rev. 32, 287-306. 
[46] Vollmer, W., Blanot, D., de Pedro, M.A. (2008). Peptidoglycan structure and architecture. FEMS Microbiol Rev. 32, 149-67.

[47] Greene, N.G., Narciso, A.R., Filipe, S.R., Camilli, A. (2015). Peptidoglycan Branched Stem Peptides Contribute to Streptococcus pneumoniae Virulence by Inhibiting Pneumolysin Release. PLoS Pathog. 11, e1004996.

[48] Henriques Normark, B., Normark, S. (2002). Antibiotic tolerance in pneumococci. Clin Microbiol Infect. 8, 613-22.

[49] Philippe, J., Gallet, B., Morlot, C., Denapaite, D., Hakenbeck, R., Chen, Y., et al. (2015). Mechanism of beta-lactam action in Streptococcus pneumoniae: the piperacillin paradox. Antimicrob Agents Chemother. 59, 609-21.

[50] Sham, L.T., Tsui, H.C., Land, A.D., Barendt, S.M., Winkler, M.E. (2012). Recent advances in pneumococcal peptidoglycan biosynthesis suggest new vaccine and antimicrobial targets. Curr Opin Microbiol. 15, 194-203.

[51] Hakenbeck, R., Bruckner, R., Denapaite, D., Maurer, P. (2012). Molecular mechanisms of betalactam resistance in Streptococcus pneumoniae. Future Microbiol. 7, 395-410.

[52] Barendt, S.M., Sham, L.T., Winkler, M.E. (2011). Characterization of mutants deficient in the L,Dcarboxypeptidase (DacB) and WalRK (VicRK) regulon, involved in peptidoglycan maturation of Streptococcus pneumoniae serotype 2 strain D39. J Bacteriol. 193, 2290-300.

[53] Sauvage, E., Kerff, F., Terrak, M., Ayala, J.A., Charlier, P. (2008). The penicillin-binding proteins: structure and role in peptidoglycan biosynthesis. FEMS Microbiol Rev. 32, 234-58.

[54] Courtin, P., Miranda, G., Guillot, A., Wessner, F., Mezange, C., Domakova, E., et al. (2006). Peptidoglycan structure analysis of Lactococcus lactis reveals the presence of an L,Dcarboxypeptidase involved in peptidoglycan maturation. J Bacteriol. 188, 5293-8.

[55] Matsuhashi, M., Takagaki, Y., Maruyama, I.N., Tamaki, S., Nishimura, Y., Suzuki, H., et al. (1977). Mutants of Escherichia coli lacking in highly penicillin-sensitive D-alanine carboxypeptidase activity. Proc Natl Acad Sci U S A. 74, 2976-9.

[56] Pericone, C.D., Overweg, K., Hermans, P.W., Weiser, J.N. (2000). Inhibitory and bactericidal effects of hydrogen peroxide production by Streptococcus pneumoniae on other inhabitants of the upper respiratory tract. Infect Immun. 68, 3990-7.

[57] Rai, P., Parrish, M., Tay, I.J., Li, N., Ackerman, S., He, F., et al. (2015). Streptococcus pneumoniae secretes hydrogen peroxide leading to DNA damage and apoptosis in lung cells. Proc Natl Acad Sci U S A. 112, E3421-30.

[58] Regev-Yochay, G., Trzcinski, K., Thompson, C.M., Lipsitch, M., Malley, R. (2007). SpxB is a suicide gene of Streptococcus pneumoniae and confers a selective advantage in an in vivo competitive colonization model. J Bacteriol. 189, 6532-9.

[59] Yesilkaya, H., Andisi, V.F., Andrew, P.W., Bijlsma, J.J. (2013). Streptococcus pneumoniae and reactive oxygen species: an unusual approach to living with radicals. Trends Microbiol. 21, 187-95.

[60] Andisi, V.F., Hinojosa, C.A., de Jong, A., Kuipers, O.P., Orihuela, C.J., Bijlsma, J.J. (2012). Pneumococcal gene complex involved in resistance to extracellular oxidative stress. Infect Immun. 80, 1037-49.

[61] Qi, Y., Grishin, N.V. (2005). Structural classification of thioredoxin-like fold proteins. Proteins. 58, $376-88$

[62] Davidson, A.L., Dassa, E., Orelle, C., Chen, J. (2008). Structure, function, and evolution of bacterial ATP-binding cassette systems. Microbiol Mol Biol Rev. 72, 317-64.

[63] Hartel, T., Klein, M., Koedel, U., Rohde, M., Petruschka, L., Hammerschmidt, S. (2011). Impact of glutamine transporters on pneumococcal fitness under infection-related conditions. Infect Immun. 79, 44-58.

[64] Kerr, A.R., Adrian, P.V., Estevao, S., de Groot, R., Alloing, G., Claverys, J.P., et al. (2004). The Ami-AliA/AliB permease of Streptococcus pneumoniae is involved in nasopharyngeal colonization but not in invasive disease. Infect Immun. 72, 3902-6.

[65] Ogunniyi, A.D., Mahdi, L.K., Trappetti, C., Verhoeven, N., Mermans, D., Van der Hoek, M.B., et al. (2012). Identification of genes that contribute to the pathogenesis of invasive pneumococcal disease by in vivo transcriptomic analysis. Infect Immun. 80, 3268-78.

[66] Brown, J.S., Gilliland, S.M., Holden, D.W. (2001). A Streptococcus pneumoniae pathogenicity island encoding an $A B C$ transporter involved in iron uptake and virulence. Mol Microbiol. 40, 572-85.

[67] Brown, J.S., Gilliland, S.M., Ruiz-Albert, J., Holden, D.W. (2002). Characterization of pit, a Streptococcus pneumoniae iron uptake ABC transporter. Infect Immun. 70, 4389-98.

[68] Lanie, J.A., Ng, W.L., Kazmierczak, K.M., Andrzejewski, T.M., Davidsen, T.M., Wayne, K.J., et al. (2007). Genome sequence of Avery's virulent serotype 2 strain D39 of Streptococcus pneumoniae and comparison with that of unencapsulated laboratory strain R6. J Bacteriol. 189, 38-51. 
[69] Yang, X.Y., He, K., Du, G., Wu, X., Yu, G., Pan, Y., et al. (2016). Integrated Translatomics with Proteomics to Identify Novel Iron-Transporting Proteins in Streptococcus pneumoniae. Front Microbiol. $7,78$.

[70] Johnston, J.W., Briles, D.E., Myers, L.E., Hollingshead, S.K. (2006). Mn2+-dependent regulation of multiple genes in Streptococcus pneumoniae through PsaR and the resultant impact on virulence. Infect Immun. 74, 1171-80.

[71] McCluskey, J., Hinds, J., Husain, S., Witney, A., Mitchell, T.J. (2004). A two-component system that controls the expression of pneumococcal surface antigen A (PsaA) and regulates virulence and resistance to oxidative stress in Streptococcus pneumoniae. Mol Microbiol. 51, 1661-75.

[72] Lawrence, M.C., Pilling, P.A., Epa, V.C., Berry, A.M., Ogunniyi, A.D., Paton, J.C. (1998). The crystal structure of pneumococcal surface antigen PsaA reveals a metal-binding site and a novel structure for a putative ABC-type binding protein. Structure. 6, 1553-61.

[73] Deplazes, E., Begg, S.L., van Wonderen, J.H., Campbell, R., Kobe, B., Paton, J.C., et al. (2015). Characterizing the conformational dynamics of metal-free PsaA using molecular dynamics simulations and electron paramagnetic resonance spectroscopy. Biophys Chem. 207, 51-60.

[74] McDevitt, C.A., Ogunniyi, A.D., Valkov, E., Lawrence, M.C., Kobe, B., McEwan, A.G., et al. (2011). A molecular mechanism for bacterial susceptibility to zinc. PLoS Pathog. 7, e1002357.

[75] Counago, R.M., Ween, M.P., Begg, S.L., Bajaj, M., Zuegg, J., O'Mara, M.L., et al. (2014). Imperfect coordination chemistry facilitates metal ion release in the Psa permease. Nat Chem Biol. 10, 35-41.

[76] Anderton, J.M., Rajam, G., Romero-Steiner, S., Summer, S., Kowalczyk, A.P., Carlone, G.M., et al. (2007). E-cadherin is a receptor for the common protein pneumococcal surface adhesin A (PsaA) of Streptococcus pneumoniae. Microb Pathogenesis. 42, 225-36.

[77] Eijkelkamp, B.A., Morey, J.R., Ween, M.P., Ong, C.L., McEwan, A.G., Paton, J.C., et al. (2014). Extracellular zinc competitively inhibits manganese uptake and compromises oxidative stress management in Streptococcus pneumoniae. PLoS One. 9, e89427.

[78] Plumptre, C.D., Eijkelkamp, B.A., Morey, J.R., Behr, F., Counago, R.M., Ogunniyi, A.D., et al. (2014). AdcA and AdcAll employ distinct zinc acquisition mechanisms and contribute additively to zinc homeostasis in Streptococcus pneumoniae. Mol Microbiol. 91, 834-51.

[79] Plumptre, C.D., Hughes, C.E., Harvey, R.M., Eijkelkamp, B.A., McDevitt, C.A., Paton, J.C. (2014). Overlapping functionality of the Pht proteins in zinc homeostasis of Streptococcus pneumoniae. Infect Immun. 82, 4315-24.

[80] Dintilhac, A., Claverys, J.P. (1997). The adc locus, which affects competence for genetic transformation in Streptococcus pneumoniae, encodes an $A B C$ transporter with a putative lipoprotein homologous to a family of streptococcal adhesins. Res Microbiol. 148, 119-31.

[81] Loisel, E., Jacquamet, L., Serre, L., Bauvois, C., Ferrer, J.L., Vernet, T., et al. (2008). AdcAll, a new pneumococcal Zn-binding protein homologous with $A B C$ transporters: biochemical and structural analysis. J Mol Biol. 381, 594-606.

[82] Bayle, L., Chimalapati, S., Schoehn, G., Brown, J., Vernet, T., Durmort, C. (2011). Zinc uptake by Streptococcus pneumoniae depends on both AdcA and AdcAll and is essential for normal bacterial morphology and virulence. Mol Microbiol. 82, 904-16.

[83] Miyaji, E.N., Oliveira, M.L., Carvalho, E., Ho, P.L. (2013). Serotype-independent pneumococcal vaccines. Cell Mol Life Sci. 70, 3303-26.

[84] Otczyk, D.C., Cripps, A.W. (2012). Vaccination for the control of childhood bacterial pneumonia Haemophilus influenzae type $b$ and pneumococcal vaccines. Pneumonia. 10, 2-18.

[85] Saxena, S., Khan, N., Dehinwal, R., Kumar, A., Sehgal, D. (2015). Conserved surface accessible nucleoside ABC transporter component SP0845 is essential for pneumococcal virulence and confers protection in vivo. PLoS One. 10, e0118154.

[86] Bidossi, A., Mulas, L., Decorosi, F., Colomba, L., Ricci, S., Pozzi, G., et al. (2012). A functional genomics approach to establish the complement of carbohydrate transporters in Streptococcus pneumoniae. PLoS One. 7, e33320.

[87] Webb, A.J., Hosie, A.H. (2006). A member of the second carbohydrate uptake subfamily of ATPbinding cassette transporters is responsible for ribonucleoside uptake in Streptococcus mutans. J Bacteriol. 188, 8005-12.

[88] Basavanna, S., Chimalapati, S., Maqbool, A., Rubbo, B., Yuste, J., Wilson, R.J., et al. (2013). The effects of methionine acquisition and synthesis on Streptococcus pneumoniae growth and virulence. PLoS One. 8, e49638.

[89] Chen, H., Ma, Y., Yang, J., O'Brien, C.J., Lee, S.L., Mazurkiewicz, J.E., et al. (2008). Genetic requirement for pneumococcal ear infection. PLoS One. 3, e2950.

[90] Molzen, T.E., Burghout, P., Bootsma, H.J., Brandt, C.T., van der Gaast-de Jongh, C.E., Eleveld, M.J., et al. (2011). Genome-wide identification of Streptococcus pneumoniae genes essential for bacterial replication during experimental meningitis. Infect Immun. 79, 288-97. 
[91] Basavanna, S., Khandavilli, S., Yuste, J., Cohen, J.M., Hosie, A.H., Webb, A.J., et al. (2009). Screening of Streptococcus pneumoniae ABC transporter mutants demonstrates that LivJHMGF, a branched-chain amino acid ABC transporter, is necessary for disease pathogenesis. Infect Immun. 77, 3412-23.

[92] Saleh, M., Abdullah, M.R., Schulz, C., Kohler, T., Pribyl, T., Jensch, I., et al. (2014). Following in Real Time the Impact of Pneumococcal Virulence Factors in an Acute Mouse Pneumonia Model Using Bioluminescent Bacteria. J Vis Exp. 84, e51174.

[93] Calbo, E., Garau, J. (2010). Of mice and men: innate immunity in pneumococcal pneumonia. Int J Antimicrob Agents. 35, 107-13.

[94] Albiger, B., Sandgren, A., Katsuragi, H., Meyer-Hoffert, U., Beiter, K., Wartha, F., et al. (2005). Myeloid differentiation factor 88-dependent signalling controls bacterial growth during colonization and systemic pneumococcal disease in mice. Cell Microbiol. 7, 1603-15.

[95] Koedel, U., Rupprecht, T., Angele, B., Heesemann, J., Wagner, H., Pfister, H.W., et al. (2004). MyD88 is required for mounting a robust host immune response to Streptococcus pneumoniae in the CNS. Brain. 127, 1437-45.

[96] Picard, C., Casanova, J.L., Puel, A. (2011). Infectious diseases in patients with IRAK-4, MyD88, NEMO, or IkappaBalpha deficiency. Clin Microbiol Rev. 24, 490-7.

[97] Picard, C., Puel, A., Bonnet, M., Ku, C.L., Bustamante, J., Yang, K., et al. (2003). Pyogenic bacterial infections in humans with IRAK-4 deficiency. Science. 299, 2076-9.

[98] von Bernuth, H., Picard, C., Puel, A., Casanova, J.L. (2012). Experimental and natural infections in MyD88- and IRAK-4-deficient mice and humans. Eur J Immunol. 42, 3126-35.

[99] Dessing, M.C., Florquin, S., Paton, J.C., van der Poll, T. (2008). Toll-like receptor 2 contributes to antibacterial defence against pneumolysin-deficient pneumococci. Cell Microbiol. 10, 237-46.

[100] Klein, M., Obermaier, B., Angele, B., Pfister, H.W., Wagner, H., Koedel, U., et al. (2008). Innate immunity to pneumococcal infection of the central nervous system depends on toll-like receptor (TLR) 2 and TLR4. J Infect Dis. 198, 1028-36.

[101] Knapp, S., Wieland, C.W., van 't Veer, C., Takeuchi, O., Akira, S., Florquin, S., et al. (2004). Tolllike receptor 2 plays a role in the early inflammatory response to murine pneumococcal pneumonia but does not contribute to antibacterial defense. J Immunol. 172, 3132-8.

[102] Koedel, U., Angele, B., Rupprecht, T., Wagner, H., Roggenkamp, A., Pfister, H.W., et al. (2003). Toll-like receptor 2 participates in mediation of immune response in experimental pneumococcal meningitis. J Immunol. 170, 438-44.

[103] McNeela, E.A., Burke, A., Neill, D.R., Baxter, C., Fernandes, V.E., Ferreira, D., et al. (2010). Pneumolysin activates the NLRP3 inflammasome and promotes proinflammatory cytokines independently of TLR4. PLoS Pathog. 6, e1001191.

[104] Sen, G., Khan, A.Q., Chen, Q., Snapper, C.M. (2005). In vivo humoral immune responses to isolated pneumococcal polysaccharides are dependent on the presence of associated TLR ligands. $J$ Immunol. 175, 3084-91.

[105] Zhang, Z., Clarke, T.B., Weiser, J.N. (2009). Cellular effectors mediating Th17-dependent clearance of pneumococcal colonization in mice. J Clin Invest. 119, 1899-909.

[106] Draing, C., Pfitzenmaier, M., Zummo, S., Mancuso, G., Geyer, A., Hartung, T., et al. (2006). Comparison of lipoteichoic acid from different serotypes of Streptococcus pneumoniae. J Biol Chem. 281, 33849-59.

[107] Hanisch, U.K., Prinz, M., Angstwurm, K., Hausler, K.G., Kann, O., Kettenmann, H., et al. (2001). The protein tyrosine kinase inhibitor AG126 prevents the massive microglial cytokine induction by pneumococcal cell walls. Eur J Immunol. 31, 2104-15.

[108] Tuomanen, E., Rich, R., Zak, O. (1987). Induction of pulmonary inflammation by components of the pneumococcal cell surface. Am Rev Respir Dis. 135, 869-74.

[109] Davis, K.M., Nakamura, S., Weiser, J.N. (2011). Nod2 sensing of lysozyme-digested peptidoglycan promotes macrophage recruitment and clearance of $S$. pneumoniae colonization in mice. J Clin Invest. 121, 3666-76.

[110] Opitz, B., Puschel, A., Schmeck, B., Hocke, A.C., Rosseau, S., Hammerschmidt, S., et al. (2004). Nucleotide-binding oligomerization domain proteins are innate immune receptors for internalized Streptococcus pneumoniae. J Biol Chem. 279, 36426-32.

[111] Hashimoto, M., Tawaratsumida, K., Kariya, H., Kiyohara, A., Suda, Y., Krikae, F., et al. (2006). Not lipoteichoic acid but lipoproteins appear to be the dominant immunobiologically active compounds in Staphylococcus aureus. J Immunol. 177, 3162-9.

[112] Zahringer, U., Lindner, B., Inamura, S., Heine, H., Alexander, C. (2008). TLR2 - promiscuous or specific? A critical re-evaluation of a receptor expressing apparent broad specificity. Immunobiology. 213, 205-24. 
[113] Ruckinger, S., van der Linden, M., Reinert, R.R., von Kries, R. (2010). Efficacy of 7-valent pneumococcal conjugate vaccination in Germany: An analysis using the indirect cohort method. Vaccine. 28, 5012-6.

[114] CDC Advisory Committee on Immunization. (2010). Updated recommendations for prevention of invasive pneumococcal disease among adults using the 23-valent pneumococcal polysaccharide vaccine (PPSV23). Morb Mortal Wkly Rep. 59, 1102-6.

[115] Feldman, C., Anderson, R. (2014). Review: current and new generation pneumococcal vaccines. J Infect. 69, 309-25.

[116] Moffitt, K.L., Malley, R. (2011). Next generation pneumococcal vaccines. Curr Opin Immunol. 23, 407-13.

[117] Darrieux, M., Goulart, C., Briles, D., Leite, L.C. (2015). Current status and perspectives on protein-based pneumococcal vaccines. Crit Rev Microbiol. 41, 190-200.

[118] Wilson, R., Cohen, J.M., Jose, R.J., de Vogel, C., Baxendale, H., Brown, J.S. (2015). Protection against Streptococcus pneumoniae lung infection after nasopharyngeal colonization requires both humoral and cellular immune responses. Mucosal Immunol. 8, 627-39.

[119] Berry, A.M., Paton, J.C. (1996). Sequence heterogeneity of PsaA, a 37-kilodalton putative adhesin essential for virulence of Streptococcus pneumoniae. Infect Immun. 64, 5255-62.

[120] Laine, C., Mwangi, T., Thompson, C.M., Obiero, J., Lipsitch, M., Scott, J.A. (2004). Age-specific immunoglobulin $\mathrm{g}(\mathrm{lgG})$ and $\lg A$ to pneumococcal protein antigens in a population in coastal kenya. Infect Immun. 72, 3331-5.

[121] Rapola, S., Jantti, V., Haikala, R., Syrjanen, R., Carlone, G.M., Sampson, J.S., et al. (2000). Natural development of antibodies to pneumococcal surface protein A, pneumococcal surface adhesin $\mathrm{A}$, and pneumolysin in relation to pneumococcal carriage and acute otitis media. J Infect Dis. 182, 1146-52.

[122] Simell, B., Korkeila, M., Pursiainen, H., Kilpi, T.M., Kayhty, H. (2001). Pneumococcal carriage and otitis media induce salivary antibodies to pneumococcal surface adhesin A, pneumolysin, and pneumococcal surface protein a in children. J Infect Dis. 183, 887-96.

[123] Zhang, Q., Choo, S., Finn, A. (2002). Immune responses to novel pneumococcal proteins pneumolysin, PspA, PsaA, and CbpA in adenoidal B cells from children. Infect Immun. 70, 5363-9.

[124] Morrison, K.E., Lake, D., Crook, J., Carlone, G.M., Ades, E., Facklam, R., et al. (2000). Confirmation of psaA in all 90 serotypes of Streptococcus pneumoniae by PCR and potential of this assay for identification and diagnosis. J Clin Microbiol. 38, 434-7.

[125] Sampson, J.S., Furlow, Z., Whitney, A.M., Williams, D., Facklam, R., Carlone, G.M. (1997). Limited diversity of Streptococcus pneumoniae psaA among pneumococcal vaccine serotypes. Infect Immun. 65, 1967-71.

[126] Talkington, D.F., Brown, B.G., Tharpe, J.A., Koenig, A., Russell, H. (1996). Protection of mice against fatal pneumococcal challenge by immunization with pneumococcal surface adhesin $A$ (PsaA). Microb Pathog. 21, 17-22.

[127] Gor, D.O., Ding, X., Briles, D.E., Jacobs, M.R., Greenspan, N.S. (2005). Relationship between surface accessibility for PpmA, PsaA, and PspA and antibody-mediated immunity to systemic infection by Streptococcus pneumoniae. Infect Immun. 73, 1304-12.

[128] Briles, D.E., Ades, E., Paton, J.C., Sampson, J.S., Carlone, G.M., Huebner, R.C., et al. (2000). Intranasal immunization of mice with a mixture of the pneumococcal proteins PsaA and PspA is highly protective against nasopharyngeal carriage of Streptococcus pneumoniae. Infect Immun. 68, 796-800.

[129] Ogunniyi, A.D., Folland, R.L., Briles, D.E., Hollingshead, S.K., Paton, J.C. (2000). Immunization of mice with combinations of pneumococcal virulence proteins elicits enhanced protection against challenge with Streptococcus pneumoniae. Infect Immun. 68, 3028-33.

[130] Briles, D.E., Hollingshead, S.K., Paton, J.C., Ades, E.W., Novak, L., van Ginkel, F.W., et al. (2003). Immunizations with pneumococcal surface protein A and pneumolysin are protective against pneumonia in a murine model of pulmonary infection with Streptococcus pneumoniae. J Infect Dis. 188, 339-48.

[131] Basset, A., Thompson, C.M., Hollingshead, S.K., Briles, D.E., Ades, E.W., Lipsitch, M., et al. (2007). Antibody-independent, CD4+ T-cell-dependent protection against pneumococcal colonization elicited by intranasal immunization with purified pneumococcal proteins. Infect Immun. 75, 5460-4.

[132] Lu, Y.J., Gross, J., Bogaert, D., Finn, A., Bagrade, L., Zhang, Q., et al. (2008). Interleukin-17A mediates acquired immunity to pneumococcal colonization. PLoS Pathog. 4, e1000159.

[133] Lu, Y.J., Forte, S., Thompson, C.M., Anderson, P.W., Malley, R. (2009). Protection against Pneumococcal colonization and fatal pneumonia by a trivalent conjugate of a fusion protein with the cell wall polysaccharide. Infect Immun. 77, 2076-83.

[134] Wang, S., Li, Y., Shi, H., Scarpellini, G., Torres-Escobar, A., Roland, K.L., et al. (2010). Immune responses to recombinant pneumococcal PsaA antigen delivered by a live attenuated Salmonella vaccine. Infect Immun. 78, 3258-71. 
[135] Oliveira, M.L., Areas, A.P., Campos, I.B., Monedero, V., Perez-Martinez, G., Miyaji, E.N., et al. (2006). Induction of systemic and mucosal immune response and decrease in Streptococcus pneumoniae colonization by nasal inoculation of mice with recombinant lactic acid bacteria expressing pneumococcal surface antigen A. Microbes Infect. 8, 1016-24.

[136] Overweg, K., Kerr, A., Sluijter, M., Jackson, M.H., Mitchell, T.J., de Jong, A.P., et al. (2000). The putative proteinase maturation protein $\mathrm{A}$ of Streptococcus pneumoniae is a conserved surface protein with potential to elicit protective immune responses. Infect Immun. 68, 4180-8.

[137] Adrian, P.V., Bogaert, D., Oprins, M., Rapola, S., Lahdenkari, M., Kilpi, T., et al. (2004). Development of antibodies against pneumococcal proteins alpha-enolase, immunoglobulin A1 protease, streptococcal lipoprotein rotamase $A$, and putative proteinase maturation protein $A$ in relation to pneumococcal carriage and Otitis Media. Vaccine. 22, 2737-42.

[138] Lebon, A., Verkaik, N.J., Labout, J.A., de Vogel, C.P., Hooijkaas, H., Verbrugh, H.A., et al. (2011). Natural antibodies against several pneumococcal virulence proteins in children during the prepneumococcal-vaccine era: the generation R study. Infect Immun. 79, 1680-7.

[139] Audouy, S.A., van Roosmalen, M.L., Neef, J., Kanninga, R., Post, E., van Deemter, M., et al. (2006). Lactococcus lactis GEM particles displaying pneumococcal antigens induce local and systemic immune responses following intranasal immunization. Vaccine. 24, 5434-41.

[140] Audouy, S.A., van Selm, S., van Roosmalen, M.L., Post, E., Kanninga, R., Neef, J., et al. (2007). Development of lactococcal GEM-based pneumococcal vaccines. Vaccine. 25, 2497-506.

[141] Brown, J.S., Ogunniyi, A.D., Woodrow, M.C., Holden, D.W., Paton, J.C. (2001). Immunization with components of two iron uptake $A B C$ transporters protects mice against systemic Streptococcus pneumoniae infection. Infect Immun. 69, 6702-6.

[142] Jomaa, M., Yuste, J., Paton, J.C., Jones, C., Dougan, G., Brown, J.S. (2005). Antibodies to the iron uptake $A B C$ transporter lipoproteins $\mathrm{PiaA}$ and PiuA promote opsonophagocytosis of Streptococcus pneumoniae. Infect Immun. 73, 6852-9.

[143] Moffitt, K.L., Gierahn, T.M., Lu, Y.J., Gouveia, P., Alderson, M., Flechtner, J.B., et al. (2011). $\mathrm{T}(\mathrm{H}) 17$-based vaccine design for prevention of Streptococcus pneumoniae colonization. Cell Host Microbe. 9, 158-65.

[144] Bologa, M., Kamtchoua, T., Hopfer, R., Sheng, X., Hicks, B., Bixler, G., et al. (2012). Safety and immunogenicity of pneumococcal protein vaccine candidates: monovalent choline-binding protein $A$ (PcpA) vaccine and bivalent PcpA-pneumococcal histidine triad protein D vaccine. Vaccine. 30, 74618.

[145] Leroux-Roels, G., Maes, C., De Boever, F., Traskine, M., Ruggeberg, J.U., Borys, D. (2014). Safety, reactogenicity and immunogenicity of a novel pneumococcal protein-based vaccine in adults: a phase I/II randomized clinical study. Vaccine. 32, 6838-46.

[146] Seiberling, M., Bologa, M., Brookes, R., Ochs, M., Go, K., Neveu, D., et al. (2012). Safety and immunogenicity of a pneumococcal histidine triad protein $D$ vaccine candidate in adults. Vaccine. 30 , 7455-60.

[147] World Health Organization. (2012). Pneumococcal vaccines WHO position paper - 2012. Wkly Epidemiol Rec. 87, 129-44. 


\section{Figures}

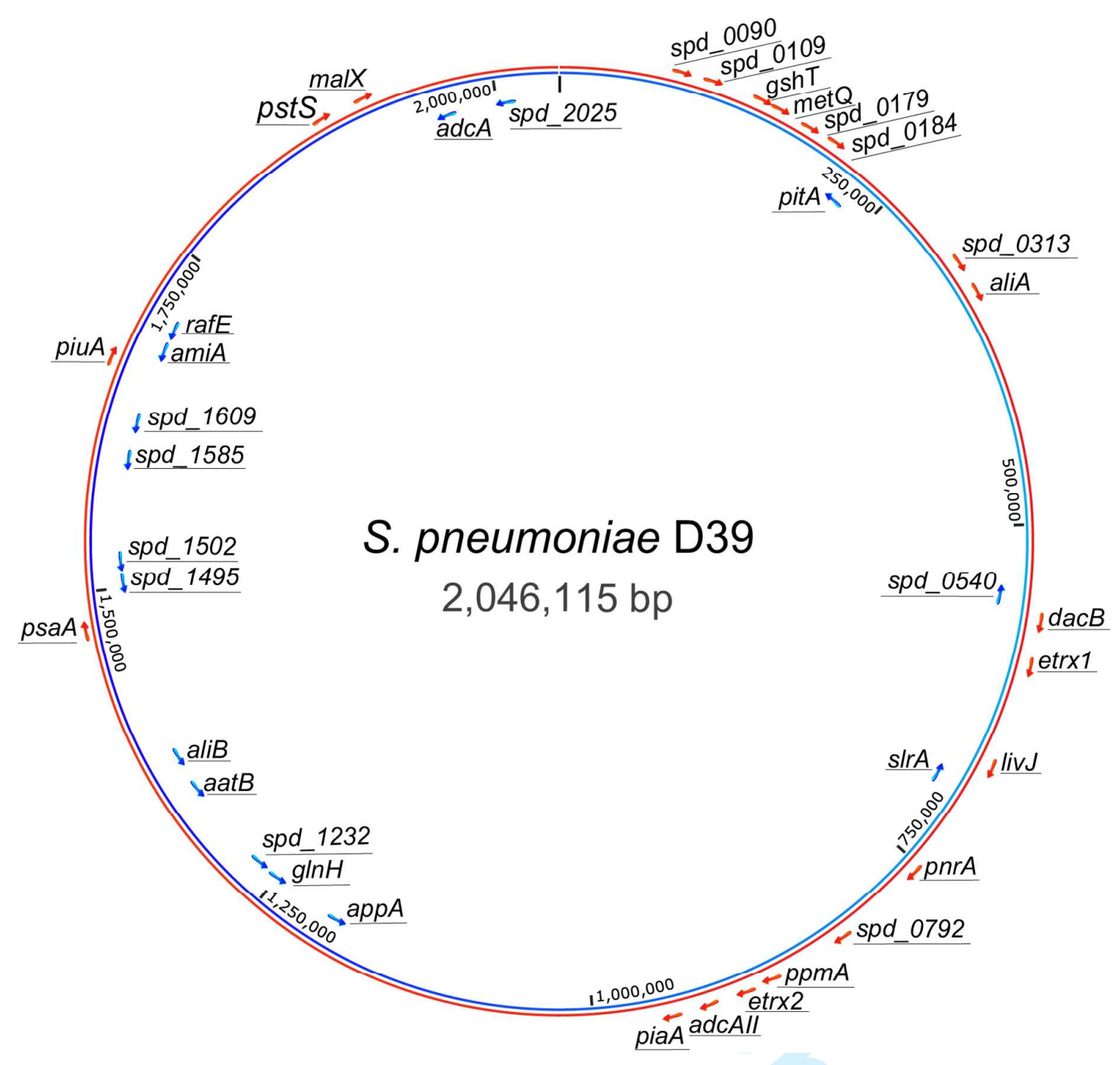

Fig. 1. Chromosomal distribution and orientation of lipoproteins in S. pneumoniae. Lipoproteins genes localization and orientation are depicted as arrows, not drawn at scale, in a circular illustration of the pneumococcal genome. The color code of the arrows and the circle represents the coding strand (red) and the reverse strand (blue). 


\section{Cytosol}

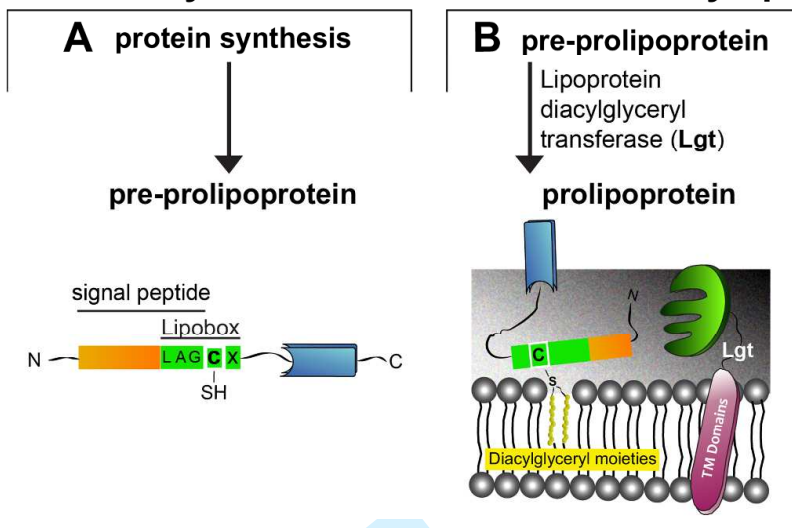

Cytoplasmic membrane

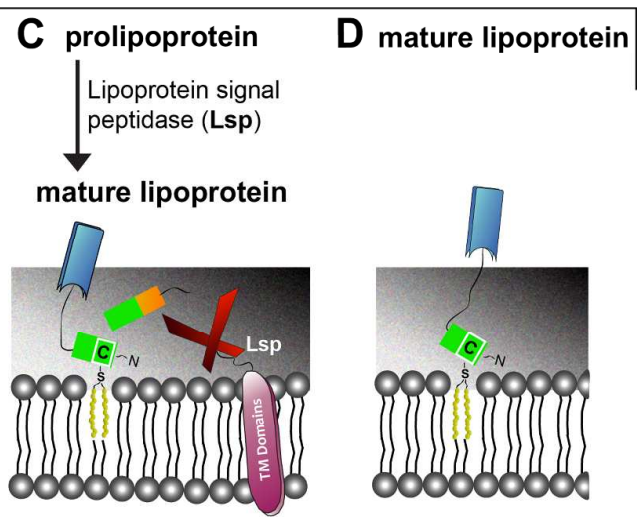

Fig. 2. Generation and processing of lipoproteins in Gram-positive bacteria.

(A) The precursor of the lipoproteins (pre-prolipoprotein) is synthesized in the cytosolic compartment of the bacterial cell with a characteristic signal peptide in the $\mathrm{N}$-terminus conformed by a conserved lipobox motif. (B) The pre-prolipoprotein is translocated across the cytoplasmic membrane by either the sec or tat pathway and is anchored to the cell membrane by the addition of diacylglyceryl moieties (lipidation) to the thiol group of an invariant cysteine residue in the lipobox via the lipoprotein diacylglyceryl transferase (Lgt). (C) Following lipidation, the signal peptide is cleaved off the prolipoprotein by the lipoprotein signal peptidase II (Lsp), resulting in a final mature lipoprotein. (D) The new mature lipoprotein has now the lipidated cysteine residue as the new $\mathrm{N}$-terminus. 

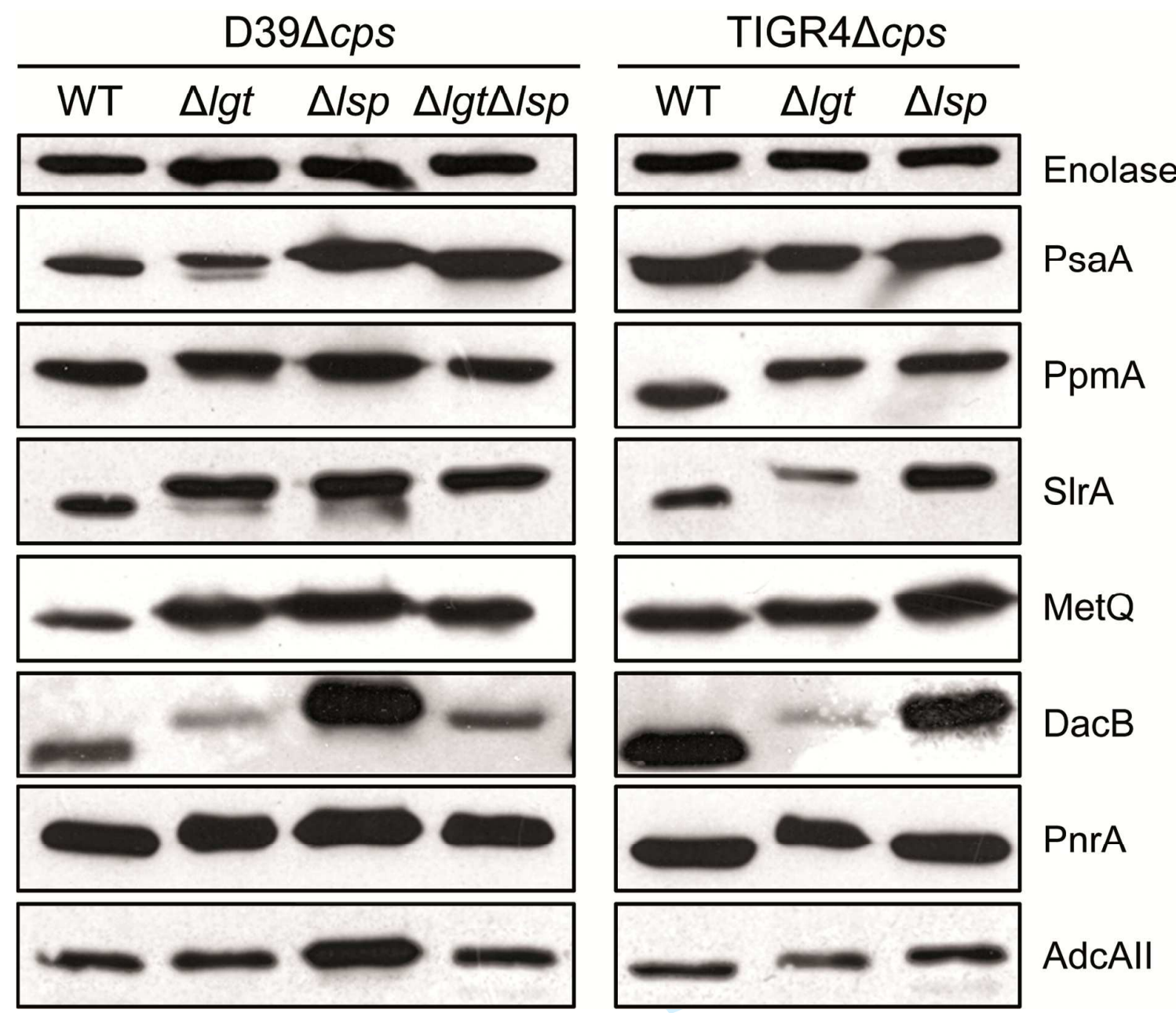

Fig. 3. Effects of mutations in the lipoprotein maturation on processing and localization of pneumococcal lipoproteins.

Immunoblot analysis of bacterial lysates from parental strains D39 $\Delta c p s$ and TIGR4 $\Delta c p s$ and their isogenic mutants D39 $\Delta c p s \Delta / g t$, D39 $\Delta c p s \Delta / s p$, D39 $\Delta c p s \Delta / g t \Delta / s p$ and TIGR4 $\Delta c p s \Delta / g t$, TIGR4 $\Delta c p s \Delta / s p$ are shown. Specific polyclonal antibodies raised against the pneumococcal lipoproteins PsaA, PpmA, SIrA, MetQ, DacB, PnrA, and AdcAll were used to study molecular weight and localization of the protein species observed in the parental strain and its mutants. Enolase acted as a loading control and was detected with a specific rabbit anti-enolase antibody. As secondary antibody a peroxidase-coupled anti-mouse or anti-rabbit antibody was used. Bacteria were cultured in THY supplemented with appropriate antibiotics, harvested at an $\mathrm{OD}_{600}$ of 0.7 , and $1 \times 10^{8}$ cells were loaded for detection. 
Table 1. Selected Non-ABC transporter lipoproteins and their impact on pneumococcal pathogenesis.

\begin{tabular}{|c|c|c|c|c|c|}
\hline $\begin{array}{l}\text { locus } \\
\text { (TIGR4/D39) }\end{array}$ & $\begin{array}{l}\text { NCBI } \\
\text { annotation }\end{array}$ & protein & description; molecular function & pathogenic function & references \\
\hline $\begin{array}{l}\text { SP_0771 } \\
\text { SPD_0672 }\end{array}$ & SPD_RS03575 & SIrA & $\begin{array}{l}\text { streptococcal lipoprotein rotamase A; } \\
\text { cyclophilin-type peptidyl-prolyl cis-trans } \\
\text { isomerase }\end{array}$ & \multirow{2}{*}{$\begin{array}{l}\text { adherence, colonization; } \\
\text { anti-phagocytosis }\end{array}$} & {$[15,19,39]$} \\
\hline $\begin{array}{l}\text { SP_0981 } \\
\text { SPD_0868 }\end{array}$ & SPD_RS04630 & $\begin{array}{l}\text { PpmA } \\
\text { (PrsA) }\end{array}$ & $\begin{array}{l}\text { putative proteinase maturation protein } \mathrm{A} \text {; } \\
\text { peptidyl-prolyl cis-trans isomerase }\end{array}$ & & {$[15,18,39]$} \\
\hline $\begin{array}{l}\text { SP_0659 } \\
\text { SPD_0572 }\end{array}$ & SPD_RS03065 & $\begin{array}{l}\text { Etrx1 } \\
\text { (TlpA) }\end{array}$ & $\begin{array}{l}\text { extracellular thioredoxin-like protein } 1 ; \\
\text { thiol-disulfide oxidoreductase }\end{array}$ & \multirow{2}{*}{$\begin{array}{l}\text { extracellular oxidative stress } \\
\text { resistance; colonization, } \\
\text { pulmonary \& systemic infection; } \\
\text { anti-phagocytosis }\end{array}$} & \multirow{2}{*}[15,21,60]{} \\
\hline $\begin{array}{l}\text { SP_1000 } \\
\text { SPD_0886 }\end{array}$ & SPD_RS04725 & Etrx2 & $\begin{array}{l}\text { extracellular thioredoxin-like protein } 2 ; \\
\text { thiol-disulfide oxidoreductase }\end{array}$ & & \\
\hline $\begin{array}{l}\text { SP_0629 } \\
\text { SPD_0549 }\end{array}$ & SPD_RS02935 & DacB & $\begin{array}{l}\text { L,D-Carboxypeptidase; Muramoyl- } \\
\text { tetrapeptide carboxypeptidase }\end{array}$ & $\begin{array}{l}\text { antibiotic resistance; adherence, } \\
\text { colonization, pulmonary \& } \\
\text { systemic infection; anti- } \\
\text { phagocytosis }\end{array}$ & {$[15,17,40,52]$} \\
\hline
\end{tabular}


Table 2. Selected $A B C$ transporter lipoproteins and their pathogenic role.

\begin{tabular}{|c|c|c|c|c|c|c|}
\hline $\begin{array}{l}\text { locus } \\
\text { (TIGR4/D39) }\end{array}$ & $\begin{array}{l}\text { NCBI } \\
\text { annotation }\end{array}$ & protein & \multicolumn{2}{|c|}{ description; substrate specificity } & pathogenic function & references \\
\hline $\begin{array}{l}\text { SP_1032 } \\
\text { SPD_0915 }\end{array}$ & SPD_RS04885 & $\begin{array}{l}\text { PiaA } \\
\text { (Pit2A) }\end{array}$ & \multicolumn{2}{|c|}{$\begin{array}{l}\text { pneumococcal iron acquisition protein } \mathrm{A} \text {; } \\
\text { iron }\end{array}$} & pulmonary \& systemic infection & {$[15,32,66]$} \\
\hline $\begin{array}{l}\text { SP_1872 } \\
\text { SPD_1652 }\end{array}$ & SPD_RS08740 & $\begin{array}{l}\text { PiuA } \\
\text { (Pit1A) }\end{array}$ & \multicolumn{2}{|c|}{$\begin{array}{l}\text { pneumococcal iron uptake protein } \mathrm{A} \text {; } \\
\text { iron }\end{array}$} & pulmonary infection & $\begin{array}{l}{[15,32,65,} \\
66]\end{array}$ \\
\hline $\begin{array}{l}\text { SP_0243 } \\
\text { SPD_0226 }\end{array}$ & SPD_RS01215 & PitA & \multicolumn{2}{|c|}{$\begin{array}{l}\text { pneumococcal iron transporter protein } \\
\mathrm{A} \text {; iron(III) }\end{array}$} & systemic infection & {$[32,67]$} \\
\hline $\begin{array}{l}\text { SP_1650 } \\
\text { SPD_1463 }\end{array}$ & SPD_RS07720 & PsaA & \multicolumn{2}{|c|}{$\begin{array}{l}\text { pneumococcal surface adhesin A; } \\
\text { manganese(II), zinc(II) }\end{array}$} & $\begin{array}{l}\text { oxidative stress resistance; } \\
\text { adherence (?), colonization; } \\
\text { pulmonary \& systemic infection }\end{array}$ & $\begin{array}{l}{[15,20,32,} \\
70-76]\end{array}$ \\
\hline $\begin{array}{l}\text { SP_2169 } \\
\text { SPD_1997 }\end{array}$ & SPD_RS10490 & AdcA & \multicolumn{2}{|c|}{ adhesin competence protein A; zinc(II) } & \multirow{2}{*}{$\begin{array}{l}\text { pulmonary \& systemic infection } \\
\text { (single mutants: attenuated; } \\
\text { double mutant: avirulent) }\end{array}$} & $\begin{array}{l}{[15,32,78-80,} \\
82]\end{array}$ \\
\hline $\begin{array}{l}\text { SP_1002 } \\
\text { SPD_0888 }\end{array}$ & SPD_RS04735 & AdcAll & \multicolumn{2}{|c|}{ adhesin competence protein All; zinc(II) } & & $\begin{array}{l}15,32,78 \\
79,81,82]\end{array}$ \\
\hline $\begin{array}{l}\text { SP_1891 } \\
\text { SPD_1671 }\end{array}$ & SPD_RS08840 & AmiA & $\begin{array}{l}\text { aminopterin resistance } \\
\text { locus protein } A\end{array}$ & \multirow{3}{*}{ oligopeptides } & \multirow{3}{*}{$\begin{array}{l}\text { colonization; systemic infection } \\
\text { (AliA) }\end{array}$} & \multirow{3}{*}{$\begin{array}{l}{[15,32,64,} \\
65]\end{array}$} \\
\hline $\begin{array}{l}\text { SP_0366 } \\
\text { SPD_0334 }\end{array}$ & SPD_RS01780 & $\begin{array}{l}\text { AliA } \\
\text { (PlpA) }\end{array}$ & $\begin{array}{l}\text { amiA-like protein } A \\
\text { (formerly permease- } \\
\text { like protein } A \text { ) }\end{array}$ & & & \\
\hline $\begin{array}{l}\text { SP_1527 } \\
\text { SPD_1357 }\end{array}$ & SPD_RS07140 & AliB & amiA-like protein B & & & \\
\hline $\begin{array}{l}\text { SP_0845 } \\
\text { SPD_0739 }\end{array}$ & SPD_RS03910 & PnrA & \multicolumn{2}{|c|}{$\begin{array}{l}\text { pneumococcal nucleoside receptor A; } \\
\text { ribonucleosides }\end{array}$} & systemic infection & $\begin{array}{l}{[15,32,85,} \\
86]\end{array}$ \\
\hline $\begin{array}{l}\text { SP_0149 } \\
\text { SPD_0151 }\end{array}$ & SPD_RS00835 & MetQ & \multicolumn{2}{|c|}{$\begin{array}{l}\text { methionine-binding lipoprotein Q; } \\
\text { D-/L-methionine, DL-homocysteine }\end{array}$} & $\begin{array}{l}\text { pulmonary \& systemic (?) } \\
\text { infection }\end{array}$ & {$[15,32,88-92]$} \\
\hline
\end{tabular}




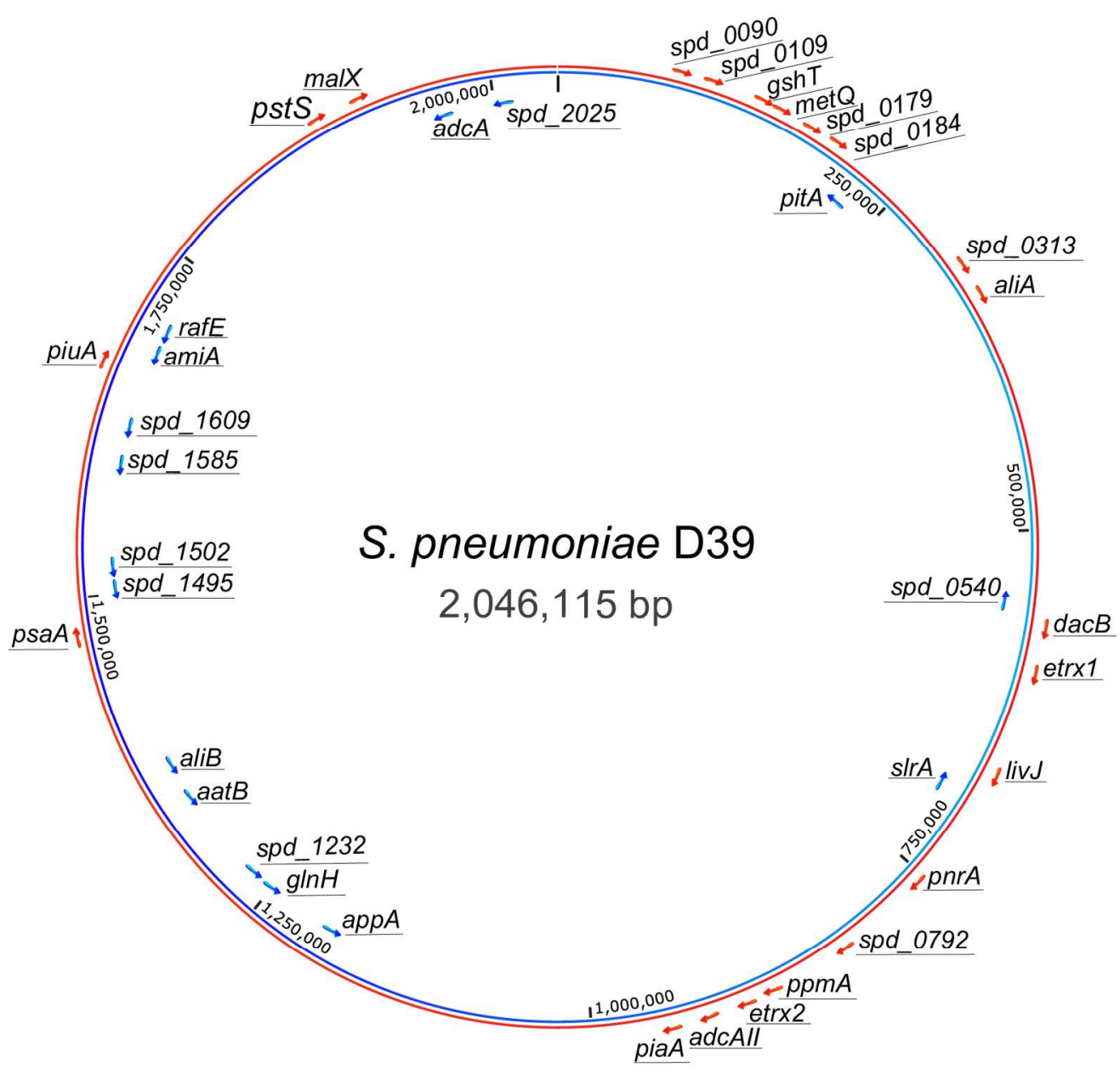

Chromosomal distribution and orientation of lipoproteins in S. pneumoniae.

Lipoproteins genes localization and orientation are depicted as arrows, not drawn at scale, in a circular illustration of the pneumococcal genome. The color code of the arrows and the circle represents the coding strand (red) and the reverse strand (blue).

Figure 1

$155 \times 147 \mathrm{~mm}(300 \times 300$ DPI $)$ 
Cytosol

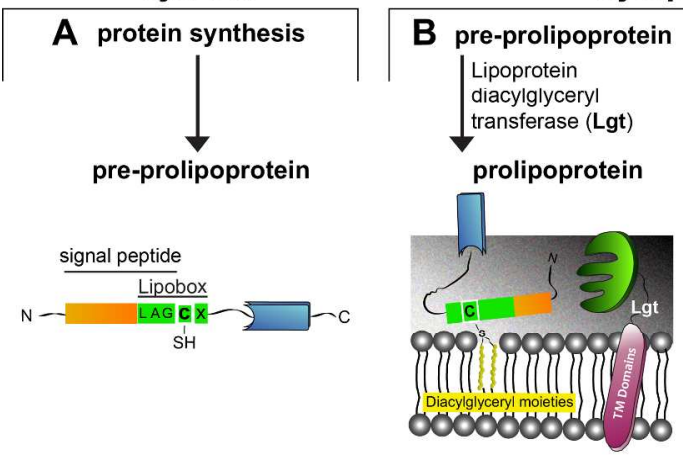

\section{Cytoplasmic membrane}

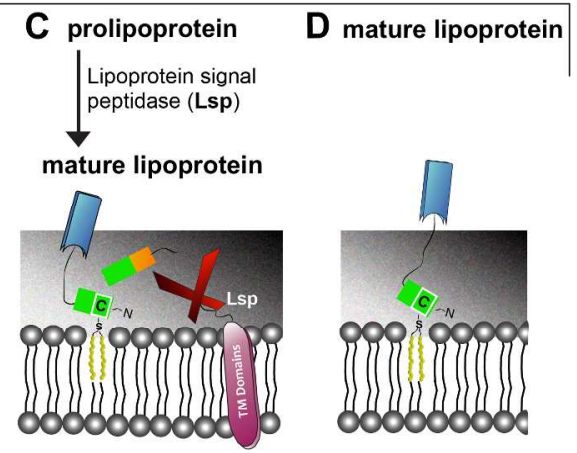

Generation and processing of lipoproteins in Gram-positive bacteria.

(A) The precursor of the lipoproteins (pre-prolipoprotein) is synthesized in the cytosolic compartment of the bacterial cell with a characteristic signal peptide in the $\mathrm{N}$-terminus conformed by a conserved lipobox motif. (B) The pre-prolipoprotein is translocated across the cytoplasmic membrane by either the sec or tat pathway and is anchored to the cell membrane by the addition of diacylglyceryl moieties (lipidation) to the thiol group of an invariant cysteine residue in the lipobox via the lipoprotein diacylglyceryl transferase (Lgt). (C) Following lipidation, the signal peptide is cleaved off the prolipoprotein by the lipoprotein signal peptidase II (Lsp), resulting in a final mature lipoprotein. (D) The new mature lipoprotein has now the lipidated cysteine residue as the new $\mathrm{N}$-terminus.

Figure 2

$255 \times 95 \mathrm{~mm}(300 \times 300 \mathrm{DPI})$ 


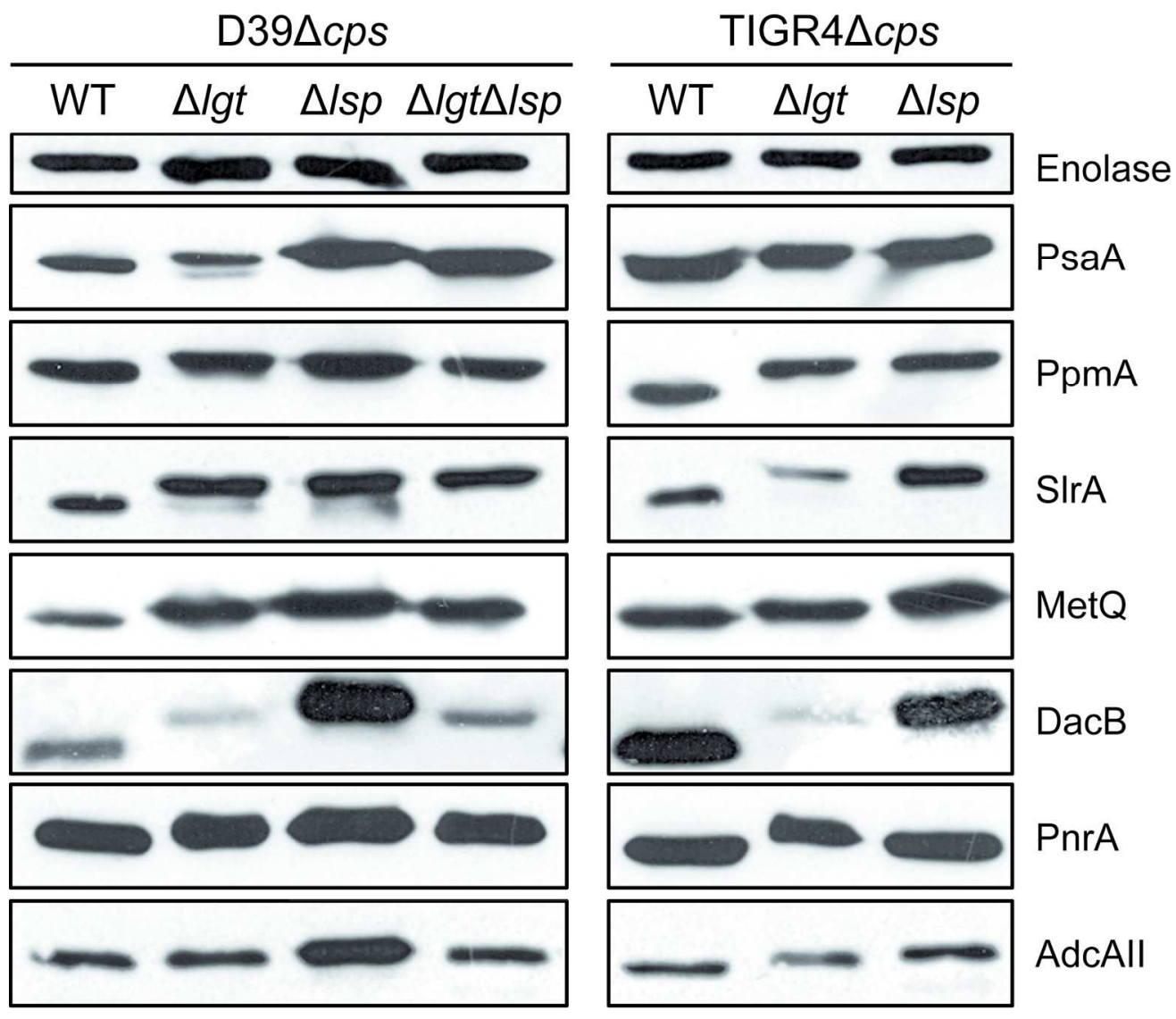

Effects of mutations in the lipoprotein maturation on processing and localization of pneumococcal

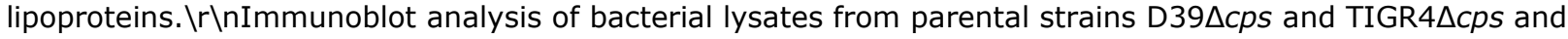
their isogenic mutants D39 $\Delta c p s \Delta / g t, \mathrm{D} 39 \Delta c p s \Delta / s p$, D39 $\Delta c p s \Delta / g t \Delta / s p$ and TIGR4 $\Delta c p s \Delta / g t$, TIGR4 $\Delta c p s \Delta / s p$ are shown. Specific polyclonal antibodies raised against the pneumococcal lipoproteins PsaA, PpmA, SIrA, MetQ,

DacB, PnrA, and AdcAII were used to study molecular weight and localization of the protein species observed in the parental strain and its mutants. Enolase acted as a loading control and was detected with a specific rabbit anti-enolase antibody. As secondary antibody a peroxidase-coupled anti-mouse or anti-rabbit antibody was used. Bacteria were cultured in THY supplemented with appropriate antibiotics, harvested at an OD600 of 0.7 , and $1 \times 10^{\wedge} 8$ cells were loaded for detection.

Figure 3

$173 \times 149 \mathrm{~mm}(300 \times 300 \mathrm{DPI})$ 